\title{
Shear and Flexural Stiffnesses of Reinforced Concrete Shear Walls Subjected to Cyclic Loading
}

\author{
T.O. Tang and R.K.L. Su ${ }^{*}$ \\ Department of Civil Engineering, The University of Hong Kong, Hong Kong, PRC
}

\begin{abstract}
Seismic analyses of concrete structures under maximum-considered earthquakes require the use of reduced stiffness accounting for cracks and degraded materials. Structural walls, different to other flexural dominated components, are sensitive to both shear and flexural stiffness degradations. Adoption of the gross shear stiffness for walls in seismic analysis prevails particularly for the design codes in the US. Yet available experimental results indicate that this could overstate the shear stiffness by more than double, which would hamper the actual predictions of building periods and shear load distributions among columns and walls. In addition, the deformation capacity could be drastically understated if the stipulated constant ductility capacity is adopted. This paper reviews the available simplified shear and flexural models, which stem from classical mechanics, empirical formulations and/or parametric studies, suitable for structural walls at the state-of-the-art. Reviews on the recommended flexural and shear stiffnesses by prominent design codes such as ACI318-11, Eurocode 8 and CSA are included. A database comprised of walls subjected to reverse-cyclic loads is formed to evaluate the performance of each model. It is found that there exist classical models that could outweigh overconservative codified values with comparable simplicity for practical uses.
\end{abstract}

Keywords: Ductility, effective stiffness, flexural stiffness, seismic, shear stiffness, shear walls, yielding.

\section{INTRODUCTION}

Structures under maximum-considered earthquakes (MCE) are always liable to cracks even within low-tomoderate seismicity regions. Appropriate definitions of effective stiffnesses for various structural members are essential to seismic analyses. However, accurate estimations of the stiffness of the member at the yield state are not straightforward. For instance, when a simple shear wall under a constant axial load is subjected to a lateral load at the top until yielding occurs at the critical section, a constant reduction factor to the gross stiffness will seldom account for the actual effective stiffness at the yield state. Despite the constitutional material properties such as the Young's modulus of the reinforcement and the concrete, there are multiple dominant factors that could influence its stiffness, including (a) the geometrical effect: low-rise squat walls (with an aspect ratio $<1.5)($ C6.7.1) [1] resist loading mainly by the strutand-tie model whereas typical shear walls (with an aspect ratio $>3$ ) resist the load by flexural action as a vertical cantilever; (b) the designed yielding mechanisms: conforming design usually requires the walls to yield in flexure so as to ensure ductile behaviour, whereas non-conforming designs without seismic details risk more adverse failures such as shear sliding failure which significantly dictate the effective stiffness at the yield state; (c) the intensity of axial loads: the stiffness deterioration in shear and flexural actions is mainly attributed to the formation of cracks; a higher axial load can effectively reduce the tensile cracks in concrete, thus increasing the effective stiffness; (d) the deterioration in stiffnesses: the degradation of effective flexural and shear stiffnesses can

*Address correspondence to this author at the Department of Civil Engineering, The University of Hong Kong, Pokfulam Road, Hong Kong, PRC; Tel: 8522859 2648; Fax: 8522559 5337; E-mail: klsu@hkucc.hku.hk be different, and bond-slip deformation can be significant for walls without proper anchorage for the reinforcement; and (e) use of special details: diagonal reinforcement details can allow better ductility by forming a more efficient strut-andtie model, whereas the effective stiffness is also enhanced due to a reduction in cracks.

Since thorough studies have been conducted on beams and columns which deform mainly in flexure, similar results and studies have been employed for walls. Most of the available design codes (e.g. ASCE41-06 [1], PEER [2], ACI31811 [3] and Eurocode 8 [4]) have accounted for the reduction in flexural stiffness by a simple reduction factor or a detailed estimation equation accounting for the effect of axial load and reinforcement ratios (e.g. Eq. (10-8) in ACI318-11 and CSA [5]) despite significant variations between these stipulated reduction factors.

Compared to flexural stiffness, limited literature has reviewed the cracked shear stiffness of reinforced concrete (RC) walls suitable for seismic analysis. Most of the available seismic codes allow no reduction in cracked shear stiffness; for instance, FEMA356 [6], ASCE41-06 [1], ACI31811 [3], Guidelines for seismic design of tall buildings by PEER (Table 7.1) [2] recommend using gross shear stiffness, whereas Eurocode 8 (cl.4.3.1(7)) [4] recommends using a 0.5 reduction factor for all stiffnesses including shear. Overconservative stiffnesses adopted in FEMA356 [6] and ASCE41-06 [1] have been highlighted by different researchers including Adebar et al. [7] and Ahmad [8]. Most seismic codes focus on effective flexural stiffness, as is the case with the latest revision made in ACI318-11 [3] which suggests that shear stiffness remains as the gross value (cl.8.8.2) or a 0.5 reduction factor is applied to all gross sectional stiffnesses similar to Eurocode 8. A recent revision of this issue 
by ATC72 [9] has commented that the limited test data and the scattering in the measured cracked shear stiffness prevent a conclusive value to be drawn, despite the fact that shear stiffness degradation can be as low as $1 / 10$ or $1 / 20$ based on RC membrane tests [9-11]. This is especially the case when diagonal cracking occurs in heavily reinforced members. Park and Paulay [12] have raised a similar issue concerning deep beams controlled by shear deformation. The reduction in stiffness can be as low as 0.15 due to radiating cracks formed at the bottom of the beam. With insufficient specific test data, Priestley et al. [13] recommend employing the same reduction factor for flexural stiffness in the shear response for low-rise squat piers of bridges. For walls that are similarly sensitive to shear deformation, a suitable cracked stiffness is crucial for seismic design in load distributions and formations of plastic mechanisms. A thorough review of existing cracked shear stiffness models is necessitated and presented herein.

This study aims to evaluate the performance of available effective stiffness models with specifications to the shear and flexure deformations. A database encompassing 43 walls subjected to reverse-cyclic loads is formed to validate each prediction model. Outperforming models suitable for practical uses with corresponding limitations are identified at the end of the paper.

\section{EFFECTIVE STIFFNESS FOR CRACKED- SECTIONS}

\subsection{Definition of Yield and Ultimate State}

The hysteretic load-displacement response of a wall under cyclic pushover experimentation can be simplified as an elastic-perfectly-plastic response, as depicted in Fig. (1). This follows the proposal by Priestley and Park [14] and has been well adopted by other researchers, e.g. $[15,16]$. The ultimate strength $\left(V_{\max }\right)$ is determined from the response envelope by averaging the peak strength in both directions. Then, the effective stiffness is determined from the secant stiffness to the experimental responses with $0.75 V_{\max }$. The elastic portion extends until it intersects with the perfectly plastic plateau at $V_{\max }$. The intersecting point defines the experimental yield displacement. The ultimate displacement is defined as where the post-peak strength drops below $80 \%$ of the $V_{\max }$

Presuming the initial stiffness $\left(K_{0}\right)$ is derived correctly from classical mechanics (e.g. Eq. (2)) or any appropriate finite element models, the suggested stiffness reduction factor in the following estimates the stiffness ratio between the secant stiffness at yield $\left(K_{\text {eff }}\right)$ and the initial stiffness, implicitly accounting for the axial load and reinforcement effects. Accurate modelling of the initial stiffness is related to the choice of finite element (e.g. 3D brick elements, 2D membrane/shell elements or even line elements with fibre sections coupled with shear springs), (b) adequate finite element discretisation, (c) correct definitions of material properties comprising but not limited to short-term Poisson's ratio and Young's modulus of steel and concrete. Details should be referred to the classical finite element textbooks and the theory of the elements in use, which are not covered here.

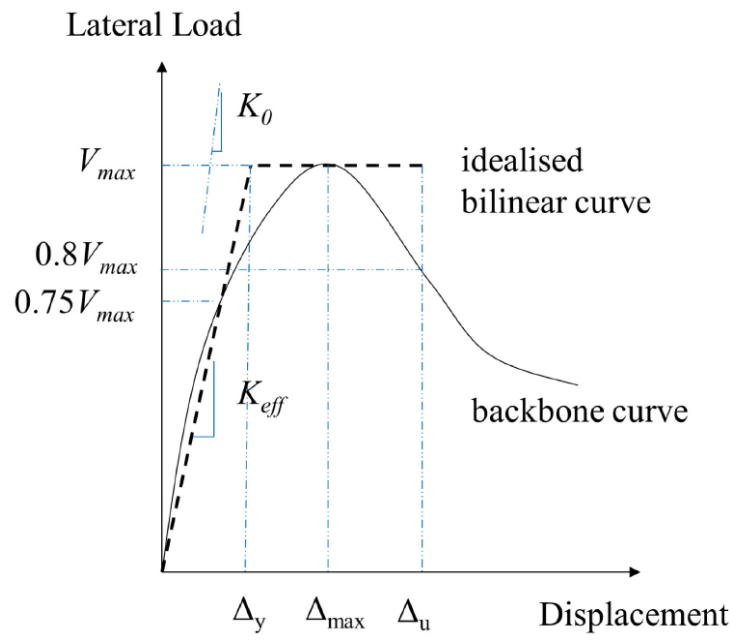

Fig. (1). Definition of yield and ultimate deformations of a wall specimen.

\subsection{Shear Stiffness}

The effective shear stiffness for the elastic range of bilinear idealisation is defined by a reduction factor $\alpha_{\mathrm{v}}$ as follows:

$k_{v, e f f}=\alpha_{v} k_{v}$

where $k_{\mathrm{v} \text {,eff }}$ denotes the secant shear stiffness at the yield state and $k_{\mathrm{v}}$ is the uncracked shear stiffness defined in Park and Paulay [12] for prismatic beam:

$k_{v}=\frac{G b_{w} d}{f \cdot h_{w}}$

where $G$ is the shear modulus of the member which can be obtained by $E_{\mathrm{c}} /(2(1+v))$ in which $E_{\mathrm{c}}$ and $v$ are the short term Young's modulus and Poisson's ratio for the concrete, respectively, $b_{\mathrm{w}}$ and $d$ denote the thickness and effective depth of the section, $h_{\mathrm{w}}$ is the total length of the beam (or the height of the wall here) and $f(=1.2$ for rectangular sections, $=1$ for flanged or barbell-shaped sections) is a factor allowing the non-uniform distribution of the shear stresses. The shear area of wall $A_{\mathrm{v}}=b_{\mathrm{w}} d$, where $d$ can be assumed as 0.8 $l_{\mathrm{w}}$ for rectangular sections (cl.11.9.4) [3] and 1.0 $l_{\mathrm{w}}$ for barbell-shaped sections. Upon loading to the member capacity, significant diagonal cracks are formed which reduce the shear stiffness. This effect is accounted for by considering the analogous truss actions reported by Park and Paulay [12]. The total shear capacity $\left(V_{\max }\right)$ is decomposed into those from the truss action $\left(V_{\mathrm{s}}\right)$ and the arch mechanism $\left(V_{\mathrm{c}}\right)$,

$V_{\max }=V_{c}+V_{s}$

Assuming 45 degree diagonal cracks and concrete struts are formed in the web, the shear stiffness of the truss $\left(k_{\mathrm{v}, 45}\right)$ under loading $V_{\mathrm{s}}$ is expressed as:

$\frac{V_{s}}{\Delta_{v}}=k_{v, 45}=\frac{\rho_{v}}{1+4 n \rho_{v}} \frac{E_{s} b_{w} d}{h_{w}}$

where $\rho_{\mathrm{v}}$ is the transverse (shear) reinforcement ratio, which can be expressed as $A_{\mathrm{sv}} /\left(\mathrm{s} \cdot b_{\mathrm{w}}\right)$, in which $A_{\mathrm{sv}}$ and $s$ are, respectively, the area and spacing of the stirrups, $n$ is the modular ratio $=E_{\mathrm{s}} / E_{\mathrm{c}}$ and $E_{\mathrm{s}}$ is the short term Young's modulus of rein- 
forcement. As a result, if the applied shear load is less than the cracking strength $\left(V_{\mathrm{cr}}\right), \alpha_{\mathrm{v}}$ would be equal to 1 , whereas if the applied load is larger than $V_{\text {cr }}$, the equivalent reduction factor for cracked shear stiffness can be estimated by:

$k_{v, \text { eff }}=\frac{V_{\max }}{\Delta_{v}}=\frac{V_{\max }}{V_{s}} k_{v, 45}$

$\alpha_{v}=\frac{V_{\max }}{V_{\max }-V_{c}} \frac{k_{v, 45}}{k_{v}}$

As the axial compression $(N)$ would close up the cracks and increase the contribution of shear resistance from concrete, Park and Paulay [12] suggested that $V_{\mathrm{c}}$ for beam proposed in ACI318-71 [17] with the consideration of axial load effects could be adopted:

$V_{c}=2\left(0.083+0.0005 \frac{N}{A_{g}}\right) \sqrt{f_{c}{ }^{\prime}} \cdot b_{w} d$

$\leq 3.5 \sqrt{f_{c}{ }^{\prime}} \cdot \sqrt{\left(0.083+0.002 \frac{N}{A_{g}}\right)} \cdot b_{w} d(\mathrm{MPa})$

where $f_{\mathrm{c}}$ ' denotes the cylinder concrete strength and $A_{\mathrm{g}}$ is the gross sectional area. The first term in Eq. (7) is derived from a conservative estimate of $V_{\mathrm{c}}$ for $\mathrm{RC}$ beams without shear reinforcement under 4-point bending [12], whereas the second term accounts for the effect of axial loads in shear resistance. Eq. (7) is consistent with the latest (cl.11.2.1.2 and cl11.2.2.2) ACI318-11 [3]. Various $V_{\mathrm{c}}$ have been proposed by different researchers and codes of practice, e.g. [13]. The New Zealand Concrete Code also introduces a reduction factor to $V_{\mathrm{c}}$ in the plastic hinge region when the axial load ratio (ALR $\left.=N / f_{\mathrm{c}}{ }^{\prime} A_{\mathrm{g}}\right) \geq 0.1$. However, those formulations result in a less satisfactory prediction of $\alpha_{\mathrm{v}}$ than using Eq. (7); thus they are not discussed here.

Provided $V_{\mathrm{c}}$ is estimated from Eq. (7), the effective shear stiffness when diagonal cracks form can be estimated from Eq. (6) as:

$\alpha_{v}=\frac{V_{\max }}{V_{\max }-V_{c}} \frac{\rho_{v}}{1+4 n \rho_{v}} \frac{E_{s}}{G} f$

If the transverse steel has yielded, $V_{\mathrm{s}}\left(=V_{\max }-V_{\mathrm{c}}\right)$ can simply be estimated from the shear steel ratio and corresponding yield strength $\left(\mathrm{f}_{\mathrm{yv}}\right)$,

$V_{s}=\rho_{v} f_{y v} \cdot b_{w} d$

According to the state-of-the-art report by Fib in 2003 [18], Priestley et al. [19] proposed a similar shear model for the design of bridge piers. The major departures from Park and Paulay's model [12] are: (a) $V_{\mathrm{c}}$ is decomposed into $V_{\mathrm{c}}$ and $V_{\mathrm{N}}$ which are the shear resistances from the concrete and axial load, respectively; (b) the inclusion of an additional term accounting for shear deformation of concrete $\left(\Delta_{\mathrm{v}}{ }^{\text {conc }}\right)$ under loading $V_{\mathrm{c}}$; and (c) shear deformation by the truss mechanism $\left(\Delta_{\mathrm{V}}{ }^{\text {truss }}\right)$ has excluded the contribution from the shortening of the concrete strut:

$\Delta_{v}^{\text {conc }}=\frac{2\left(V_{c}+V_{N}\right)}{G 0.8 A_{g}} \cdot L_{s} \frac{V_{\max }}{V_{y}}$
$\Delta_{v}^{\text {truss }}=\frac{V_{s} \cdot s}{E_{s} A_{s v}\left(d-d^{\prime}\right)} \cdot L_{s} \frac{V_{\max }}{V_{y}}$

for $V_{s}=V_{y}-V_{c}-V_{N} \geq 0$

$V_{c}=0.29 \sqrt{f_{c}{ }^{\prime}} \cdot 0.8 A_{g}$

$V_{N}=\frac{N(d-c)}{2 L_{s}}$

where shear stiffness of concrete is defined as half of the gross value $(G / 2), 0.8 A_{\mathrm{g}}$ accounts for the non-uniform shear stresses distribution, $c$ is the length of the compression zone for the concrete strut at the base ( $\approx 0.2 l_{\mathrm{w}}$ for walls [16]), $A_{\mathrm{sv}}$ is the area of each stirrup, $d^{\prime}$ is the effective depth of the compression reinforcement, and $L_{\mathrm{s}}$ is the shear span. Provided the shear strength at yield $\left(V_{\mathrm{y}}\right)$ is equal to nominal shear strength $\left(V_{\max }\right)$ and $d^{\prime} \approx 0$, the shear deformation at the yield state $\left(\Delta_{\mathrm{v}}=\Delta_{\mathrm{v}}{ }^{\text {conc }}+\Delta_{\mathrm{v}}{ }^{\text {truss }}\right)$ is reduced to:

$$
\begin{aligned}
& \Delta_{v}=\frac{0.58 \sqrt{f_{c}{ }^{\prime}}}{G} \cdot L_{s}+\frac{N(d-c)}{G 0.8 A_{g}}+\frac{V_{s}}{E_{s} \rho_{v} b_{w} d} \cdot L_{s} \\
& \alpha_{v}=\frac{v_{\max }}{\frac{0.58 \sqrt{f_{c}{ }^{\prime}}}{1} \cdot \frac{L_{s}}{h_{w}}+\frac{N}{0.8 A_{g}} \frac{(d-c)}{h_{w}}+\frac{G}{E_{s}} \frac{V_{s}}{\rho_{v} b_{w} d} \cdot \frac{L_{s}}{h_{w}}} f
\end{aligned}
$$

The above formulation is valid only when $V_{\mathrm{s}} / A_{\mathrm{sv}} \leq f_{\mathrm{yv}}$, otherwise the yielding of stirrups results in the prevalence of shear failure.

The most recent shear wall model was proposed by Krolicki et al. [16]. With modifications to the column models from Miranda et al. [20] and the USCD model from Priestley et al. [15], a full shear response envelope is defined to account for walls subjected to pre-emptive shear or flexureshear failure and has been verified against 26 wall specimens subjected to limited ALR $\leq 0.06$.

At the onset of flexural first yield (applied shear load $=F_{y}$ ), defined by the first occurrence of yielding in the longitudinal steel or yield strain in concrete $=0.002$, the proposed effective shear stiffness follows the same definition as Eq. (4) by Park and Paulay [12]. However, the shear resistance by the truss mechanism $\left(V_{\mathrm{s}}\right)$ is defined differently:

$V_{s}=F_{y}-V_{c, s c}$

where $V_{\mathrm{c}, \mathrm{sc}}$ is the shear resistance by concrete when shear cracks occur:

$V_{c, s c}=\alpha_{p} \beta \gamma_{p} \sqrt{f_{c}{ }^{\prime}}\left(0.8 A_{g}\right)$

The coefficient $\alpha_{p}$ denotes the effect of shear-span-todepth ratio $\left(L_{\mathrm{s}} / l_{\mathrm{w}}\right)$; the coefficient $\beta$ accounts for the beneficial effect in shear resistance with an increasing volumetric ratio of longitudinal steel, which is a constant in the USCD model [15]; the coefficient $\gamma_{p}$ denotes degradation in shear strength with increasing displacement ductility $\left(\mu_{\Delta}\right)$, $\gamma_{p}=0.29 \mathrm{MPa}$ for $\mu_{\Delta} \leq 2, \gamma_{p}=0.05 \mathrm{MPa}$ for $\mu_{\Delta} \geq 6.0$, and values in between are interpolated.

$\alpha_{p}=3-\frac{L_{s}}{l_{w}} \geq 1.0$ 
$\beta=0.5+20 \rho_{s l} \leq 1.0$

where $\rho_{\mathrm{s} 1}$ is the longitudinal steel ratio. After the onset of first flexural yield, the shear stiffness remains unchanged until attaining the nominal shear strength $\left(V_{\max }\right)$. Thus, the shear stiffness reduction factor at the yield state is:

$\alpha_{v}=\frac{F_{y}}{F_{y}-V_{c, s c}} \frac{\rho_{v}}{1+4 n \rho_{v}} \frac{E_{s}}{G} f$

$F_{\mathrm{y}}$ can be rigorously obtained from section analysis programmes by defining the concrete and longitudinal steel properties. Since $\alpha_{\mathrm{v}}$ is relatively insensitive to $F_{\mathrm{y}}$, it can be assumed to be approximately $0.75 V_{\max }$ without introducing a significant error. The factor of 0.75 is determined by performing the section analysis on squat walls with evenly distributed longitudinal steel and ALR $=0.1$. The major difference between Eq. (20) and Eq. (8) is that the shear resistance of the axial load has not been excluded for $V_{\mathrm{s}}$ in Eq. (20). Fig. (2a-c) summarise the differences between the aforementioned approaches.

Based on cyclic tests of 11 squat walls that failed in flexure or shear sliding modes [21] and truss analogy, Salonikios [22] proposed an analytical equation to estimate the shear deformation of walls when diagonal shear cracking occurs.

$\Delta_{v}=\frac{d}{2 E_{s}}\left(\frac{V_{s, w}}{A_{s v}}+\frac{\sqrt{2} V_{s, d}}{A_{s d}}\right) \frac{\mathrm{a}_{s}^{2}}{2.25}$

where $A_{s v}$ and $A_{s d}$ are, respectively, the area of conventional shear reinforcement and diagonal reinforcement, $V_{s, w}$ and
$V_{s, d}$ are the shear forces resisted correspondingly and $\mathrm{a}_{\mathrm{s}}$ denotes the aspect ratio of the specimen. For walls with conventional web reinforcement and yielding in the shear steel $\left(V_{s, w}=f_{y v} A_{s v}\right)$, the effective stiffness for shear can be simplified as:

$$
\begin{aligned}
& k_{v, \text { eff }}=\frac{V_{\max }}{\Delta_{v}}=V_{\max } \frac{4.5 E_{s}}{d \mathrm{a}_{s}^{2} f_{y v}} \\
& \alpha_{v}=\frac{V_{\max }}{b_{w} d f_{y v}} \frac{E_{s}}{G} \frac{4.5}{\mathrm{a}_{s}} \frac{l_{w}}{d} f \\
& \text { or } \alpha_{v}=\frac{v_{\max } / G}{\varepsilon_{y v}} \frac{4.5}{\mathrm{a}_{s}} \frac{l_{w}}{d} f
\end{aligned}
$$

where $l_{w}$ is the total depth of the wall section, $v_{\max }$ is the averaged shear stress $\left(V_{\max } / b_{w} d\right)$ of the section and $\varepsilon_{y v}$ is the yield strain of the transverse steel. Unlike the estimations by Park and Paulay [12] and Krolicki et al. [16], the $\alpha_{\mathrm{v}}$ here is inversely proportional to the square of the shear $\operatorname{span}\left(V_{\max }=\right.$ $\left.M_{\max } / L_{\mathrm{s}}, \mathrm{a}_{\mathrm{s}}=L_{\mathrm{s}} / l_{\mathrm{w}}\right)$ if the nominal shear strength is controlled by the flexural capacity $\left(M_{\max }\right)$.

Besides the truss analogy model, Gérin and Adebar [10] proposed a general model, based on the force equilibrium and strain-compatibility of Mohr's circle, to predict the loaddeformation response of conventionally reinforced concrete membrane elements under reverse-cyclic loads. Instead of treating the element as a homogenous material, the proposed approach introduces crack deformations to maintain the strain compatibility between the concrete and the reinforce-
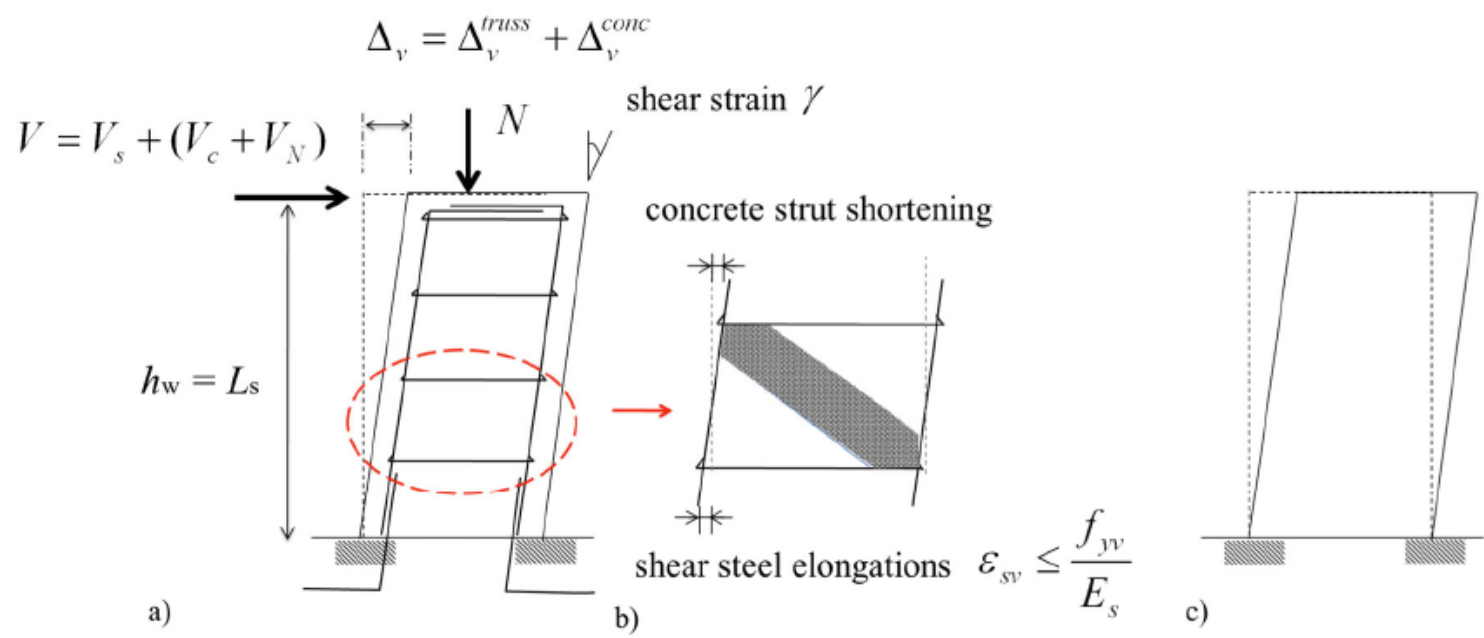

b)

c)

\begin{tabular}{|l|c|c|}
\multicolumn{2}{c}{ Truss Mechanism* } & Shear Beam Mechanism \\
\hline Park and Paulay (1975) & $V_{\mathrm{s}}$ & -- \\
\hline Priestley et al. (1996) & $V_{\mathrm{s} \text { (ignore concrete strut shortening) }}$ & $V_{\mathrm{c}}+V_{\mathrm{N}}$ \\
\hline Krolicki et al. (2011) & $V_{\mathrm{s}}+V_{\mathrm{N}}$ & -- \\
\hline $\begin{array}{l}\left.\text { Notes: }{ }^{*}\right) V_{\mathrm{s}}=\text { strength of truss mechanism if it is expected to yield; } V_{\mathrm{s}}=V-\left(V_{\mathrm{c}}+V_{\mathrm{N}}\right) \text { if shear failure is not } \\
\text { expected with sufficient shear steel. }\end{array}$ \\
\hline
\end{tabular}

Fig. (2). Shear deformation mechanisms of RC walls at the yield states: (a) overall deformation, contributions by (b) truss mechanism, and (c) shear beam mechanism. 
ment. The predicted shear stiffness accounts for the quantity and yield strain of the reinforcement and the applied axial stress.

$G_{e f f}=\frac{v_{\max }}{\gamma_{y}}\left(\right.$ i.e., $\left.\alpha_{v}=\frac{G_{e f f}}{G}\right)$

where $v_{\max }$ and $r_{\mathrm{y}}$ are, respectively, the nominal shear strength and shear strain of the element. The nominal shear strength can be determined from codes, e.g. ACI318-11 [3]. For shear dominated elements such as squat walls with slight axial loads, it can be defined as [10]:

$v_{\max }=0.25 \sqrt{f_{c}{ }^{\prime}}+\rho_{v} f_{y v}$

where $f_{y v}$ and $\rho_{v}$ are respectively the yield strength and reinforcement ratio for the transverse steel of the wall. As the shear strain increases proportionally to the strain of the weaker reinforcement, the shear strain for the crackedsection is defined as the onset of the yielding of the weaker transverse reinforcement for walls.

$\gamma_{y}=\frac{f_{y v}}{E_{s}}+\frac{v_{\max }-n_{a}}{\rho_{s l} E_{s}}+\frac{4 v_{\max }}{E_{c}}$

for $0 \leq \frac{v_{\max }-n_{a}}{\rho_{s l} E_{s}} \leq \frac{f_{y l}}{E_{s}}$

where $n_{a}$ is the applied axial stress on the element (compression as positive) and $f_{y l}$ and $\rho_{s l}$ denote the yield strength and reinforcement ratio for the longitudinal steel, respectively. The contribution of each term to the overall shear strain is explained in Fig. (3a-c). It should be noted that the above formulation provides the lower-bound estimate of the shear stiffness particularly for slender walls, as transverse steel yielding and flexural cracks usually concentrate at the lower region of the wall. There are other available analytical models and experimental tests for determining the post-cracking shear stiffness of RC membranes. The $G_{\text {eff }} G$ measured from those membrane tests can be as low as 0.1 to 0.05 of the gross value [11] which is not frequently observed for wall tests. This can be attributed to the aforementioned damage localisation issue.

\subsection{Flexural Stiffness}

For a prismatic member, the top loaded stick model with lumped plasticity at the base has prevailed in the literature and has often been used for studying the flexural mechanism. An example is illustrated in Fig. (4). Since the curvature is essentially proportional to the applied moment, the curvature distribution is almost triangularly distributed along the height of the member. At the yield state, the base curvature is assumed to reach yield curvature $\left(\varphi_{y}\right)$ which is usually defined as the onset of concrete nonlinearity (the maximum strain in concrete $\varepsilon_{c}=\varepsilon_{c . y}$ ) or flexural steel yielding (the maximum strain in flexural steel $\varepsilon_{s l}=f_{y l} / E_{s}$ ) [18]. Hence, the curvature equivalent to the strain gradient at the critical section can be calculated as:

$$
\varphi_{y}=\min \left\{\frac{f_{y l}}{E_{s}} \cdot \frac{1}{d-x_{y}}, \frac{\varepsilon_{c, y}}{x_{y}}\right\}
$$

where $\varepsilon_{c, y}=0.75$ strain of concrete at the peak stress, $f_{y l}$ is the yield strength of the flexural steel and $x_{y}$ is the neutral axial depth. Fig. (4b) depicts the curvature distribution at the yield state. At the upper region of the member, the section remains uncracked and the actual curvature developed is smaller, whereas near the wall base, flexural-shear cracks occur which causes an increase in curvature along the member and is regarded as tension shift. Priestley et al.(Section 6.2.1) [15] concluded that an upward shift of $l_{\mathrm{w}} / 2$ (e.g. one-tenth of
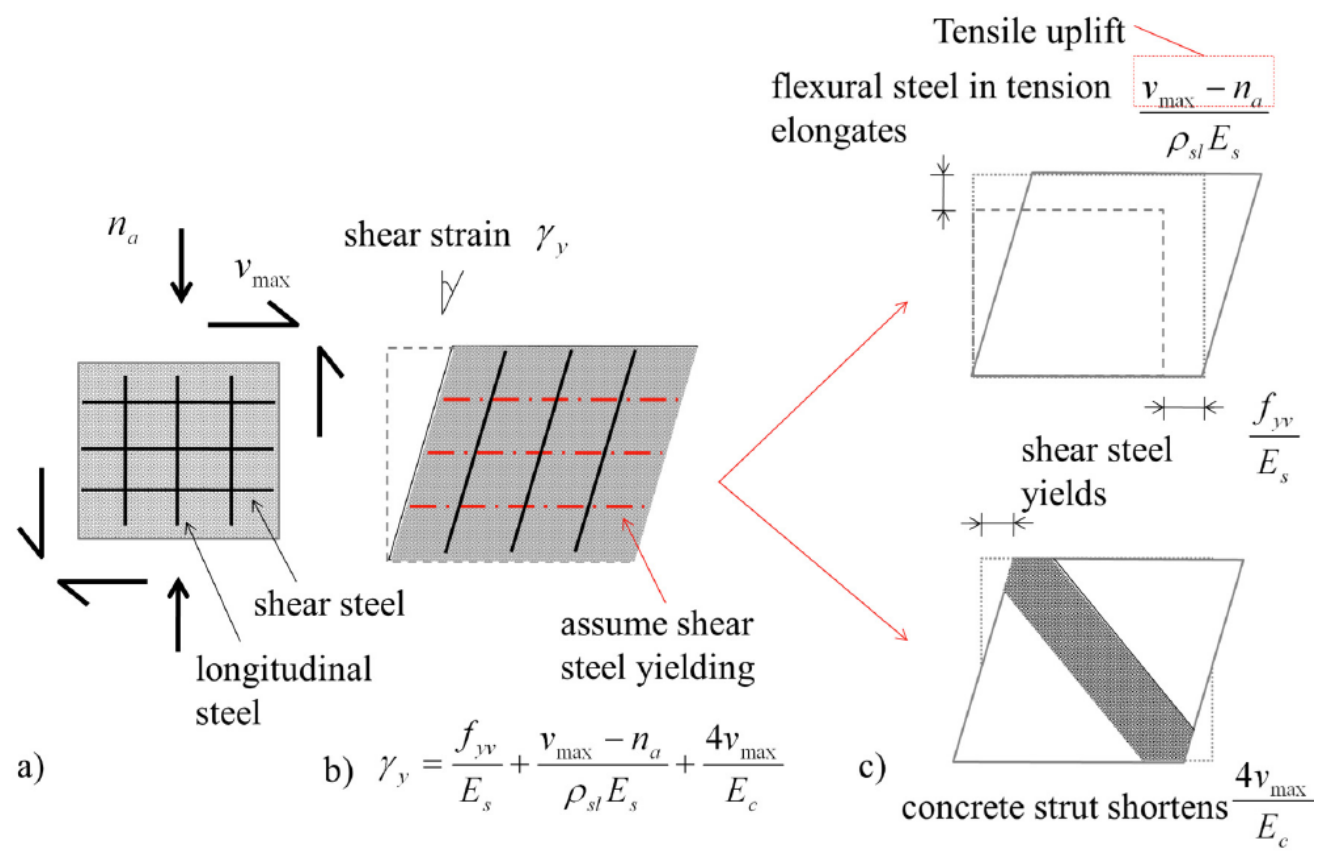

Fig. (3). Shear deformation mechanisms of RC membranes at the yield states: (a) before deformation, (b) after shear deformation, and (c) contributions to shear deformations from various components. 
the total building height for walls with aspect ratio $=5$ ) of the curvature distribution can be reasonably assumed. In cases of triangularly loaded members, a linear idealisation of yield curvature along height is suitable to compensate the effects of tension shift and uncracked stiffness (curvature reduces to only one-fourth along 0.5 total building height from the top) so as to restore an equivalent displacement at the effective building height (= 0.7 total building height).

With increased loading at the top, plastic curvature would concentrate near the base of the member. The ultimate curvature is reached when the maximum strain in concrete reaches the ultimate strain corresponding to the degraded strength of 0.85 of the peak strength of confined concrete [18].

$\varphi_{u}=\frac{\varepsilon_{c, u}}{x_{u}}$

where subscript $u$ denotes the properties at the ultimate state. The distribution of plastic curvature is usually idealised as a parallelogram as shown in Fig. (4c). The top plastic deflection $\left(\Delta_{\mathrm{p}}^{\mathrm{f}}\right)$ can then be correlated to the plastic rotation $\left(=\varphi_{p}\right.$ $\left.l_{p h}\right)$ at the base:

$\Delta_{p}^{f}=\varphi_{p} l_{p h} \cdot\left(h_{w}-\frac{l_{p h}}{2}\right)$

where the height of members $h_{\mathrm{w}}$, and $l_{\mathrm{ph}}$ is the length of the plastic hinge. The above model provides a brief review of the flexural mechanism in prismatic walls. It is noted that other studies, e.g. $[15,18]$, provide similar estimations to $l_{\mathrm{ph}}$ and the stick model mechanism. Since most of the experimental results provide only the moment-curvature responses, instead of strain dependence, yield and ultimate curvatures are determined from the applied moment in compliance with Fig. (1). The effective flexural stiffness at the yield state $\left(E I_{\text {eff }}\right)$ can be derived by:

$E I_{\text {eff }}=\frac{M_{\max }}{\varphi_{y}}$
Thus, it can be quantified by a reduction factor $\left(\alpha_{f}\right)$ applied to the gross sectional properties as:

$E I_{\text {eff }}=\alpha_{f} E_{c} I_{g}$

where $I_{\mathrm{g}}$ denotes the gross moment of inertia of the uncracked section without considering the effect of longitudinal reinforcement.

One of the earliest references accounting for the reduction in flexural stiffness due to cracks can be dated back to ACI318-71 [17]. The effective flexural stiffness for a prismatic member with tensile cracks under bending may follow:

$$
\begin{aligned}
& I_{e}=\left(\frac{M_{c r}}{M}\right) I_{g}+\left[1-\left(\frac{M_{c r}}{M}\right)^{3}\right] I_{c r} \text { for } M \geq M_{c r} \\
& M_{c r}=\frac{f_{r} I_{g}}{l_{c t}}
\end{aligned}
$$

where $M$ is the applied moment and the corresponding moment of inertia $\left(I_{e}\right)$ is lying between uncracked $\left(I_{g}\right)$ and fully cracked values $\left(I_{c r}\right), l_{c t}$ denotes the depth from the centroid of the section to extreme tension fibre $\left(=l_{w} / 2\right.$ for rectangular section) and $f_{r}$ is the modulus of rupture of concrete $=$ $0.62 \sqrt{ } f_{c}$, for normal weight concrete. At the yield state, the effective flexural rigidity $\left(E I_{\text {eff }}\right)$ can be determined by using $M=M_{\max }$ for members designed to yield in flexure. The above expression is an empirical prediction which stems from the study by Branson and Heinhrich [23] on simply/continuously supported rectangular and T-shaped beams. The $I_{c r}$ has to be determined by principles using Eq. (28) and Eq. (31).

Since then, continuous tests have been conducted on different components including structural walls. Yet significant variations in suggested effective flexural stiffness for walls remain amongst different codes. For instance, Eurocode 8 (cl.4.3.1(7)) [4] suggests a reduction factor $\left(\alpha_{f}\right)$ of 0.5 , whereas FEMA356 [6] and ASCE41-06 [1] allow a factor of

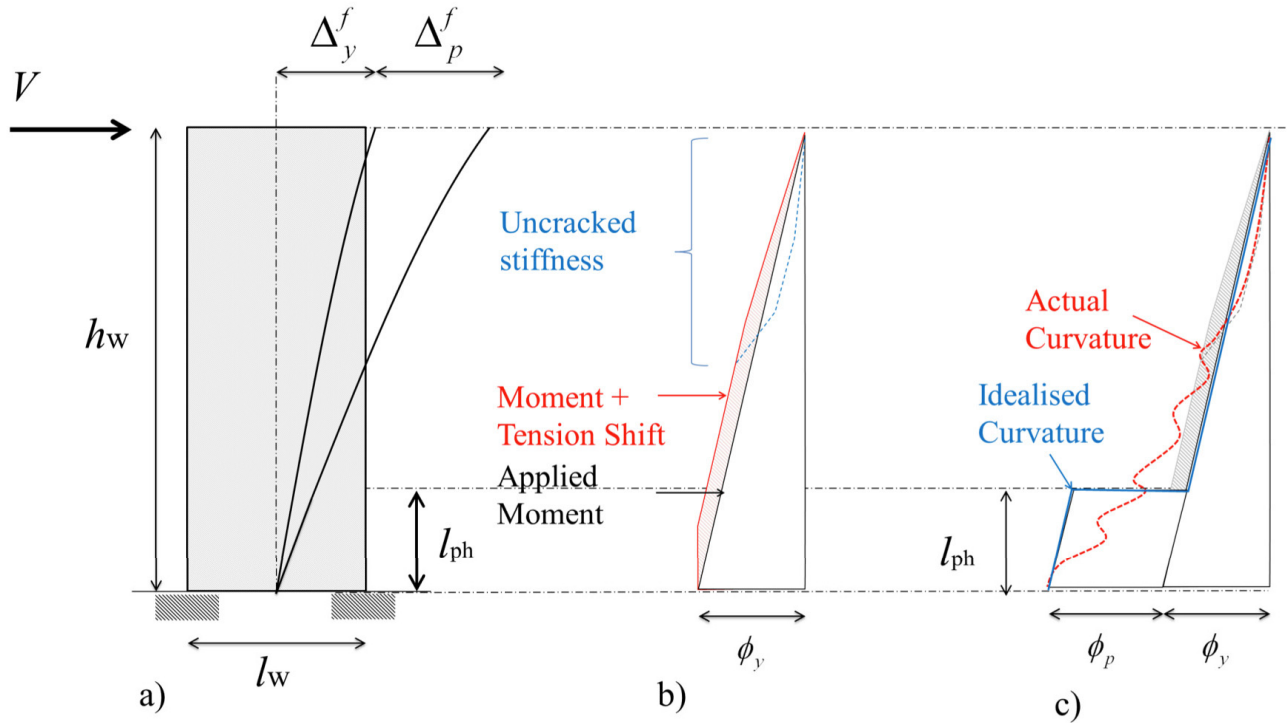

Fig. (4). Flexural deformation mechanism of RC walls at the yield and ultimate states: (a) flexural deformation profile; and curvature distribution, (b) at yield state, and (c) ultimate state. 
0.8 for uncracked sections and 0.5 for cracked sections in which the cracked sections are determined by checking the load demands against the modulus of rupture of concrete. ACI318-11 (cl.10.10.4.1) [3] has revised the values to 0.7 for uncracked walls and to 0.35 for cracked walls, respectively. Alternatively, Eq. (10-8) of ACI318-11 [3] allows a detailed estimation of effective stiffness for walls under compressions, which stems from the studies by Khuntia and Ghosh [24] on RC beams and columns:

$$
I_{e f f}=\left(0.8+25 \rho_{s l}\right)\left(1-\frac{M}{l_{w} N}-0.5 \frac{N}{N_{0}}\right) I_{g}
$$

for $0.35 I_{g} \leq I_{\text {eff }} \leq 0.875 I_{g}$

where $N_{0}$ is the nominal axial strength when axial load is applied with zero eccentricity. Since $M /\left(l_{\mathrm{w}} N\right)$ becomes relatively large in cases of small axial loads, an effective flexural stiffness of $0.35 I_{g}$ is usually assumed for these cases. For non-prestressed members with conforming transverse steel, $N_{0}$ can be estimated from Eq. (10-2) in ACI318-11 [3]:

$N_{0}=0.8\left[0.85 f_{c}{ }^{\prime} A_{g}\left(1-\rho_{s l}\right)+f_{y l} A_{g} \rho_{s l}\right]$

Based on the experimental results of high-rise core walls (aspect ratios $\geq 2$ ), Adebar et al. [7] propose a more detailed guideline by stating the upper and lower-bound stiffnesses:

Upper-bound $I_{e f f}=\left(0.6+\frac{N}{f_{c}{ }^{\prime} A_{g}}\right) I_{g} \leq I_{g}$

Lower-bound $I_{e f f}=\left(0.2+2.5 \frac{N}{f_{c}{ }^{\prime} A_{g}}\right) I_{g} \leq 0.7 I_{g}$

They emphasise the intensity of axial loads in controlling the cracks, similar to the detailed estimation by ACI318-11 in Eq. (35); thus less reduction is required for the flexural stiffness. Eqs. (37) and (38) successfully bound the experimental results by Adebar et al. [7], which found that the upper-bound stiffness could be used if the wall displacement was within 0.2 times of the yield drift, and the lower-bound stiffness closely matched the wall stiffness at yield. They are also recommended in ATC-72 [9] and CSA [5], which state that the lower bound stiffness is appropriate for walls under maximum-considered earthquake-level (MCE) analyses. Adebar et al. [7] suggested that the lower-bound stiffness values could possibly be increased for walls under higher axial loads. However, there are insufficient test data to verify it.

Ahmad [8] has recently conducted a review on the flexural stiffness of walls at various limit states. He discovered over-conservatism for wall stiffness in ACI318 [3]. Two approaches comprising an implicit method and an explicit method have been proposed to estimate the reduction in flexural stiffness. Only the second method is discussed here, whereby the reduction factor $\left(\alpha_{f}\right)$ is applied to the whole section of the wall to implicitly account for the shift of the centroid for cracked walls. Based on the regression analyses of parametric studies, Ahmad proposed:

$\alpha_{f}=\frac{I_{e f f}}{I_{g}}=\frac{I_{c r}}{I_{g}}+\left(\frac{I_{g n l}}{I_{g}}-\frac{I_{c r}}{I_{g}}\right) k_{1}$ where $I_{c r}$ is the cracked moment of inertia of the cross section, $I_{g n l}$ accounts for the effect of axial strain on the gross moment of inertia and coefficient $k_{1}$ accounts for the tensionstiffening effects. Without repeating the complicated derivations, details of Eq. (39) may be found in his paper (Eqs. 16 to 24) [8].

Other noteworthy research on estimating the flexural stiffness of walls includes the study by Bachmann [25], where he recommended using:

$\alpha_{f}=\frac{12}{\kappa_{1}} \frac{E_{s}}{E_{c}}\left[\rho_{s l} \xi \eta+n_{a r} \eta^{\prime} \frac{f_{c}^{\prime}}{f_{y l}}\right]$

where $\rho_{s l}$ is the longitudinal steel ratio, $n_{a r}$ is the ALR, $\eta$ is the ratio of neutral axis depth to wall length and $\xi$ is the ratio of internal lever arm to wall length. The equation is further simplified by assuming coefficient $\kappa_{1}=2, \eta=0.55, \eta^{\prime}=0.4$, $\xi=0.9, E_{s} / E_{c}=6$ and $f_{c}^{\prime} / f_{y l}=1 / 12$. Thus Eq. (12) can be rewritten as [26]:

$\alpha_{f}=0.0018 \rho_{v}+0.00012 n_{a r}$

Priestley et al. [15] proposed a prominent concept of constant yield curvature for structural components under various reinforcement ratios, whereby the effective stiffness should be directly proportional to the nominal flexural capacity. A simple estimation of yield curvature of rectangular walls was proposed by Priestley and Kowalsky [27] based on numerical section analyses:

$\varphi_{y}=\frac{2 \varepsilon_{y l}}{l_{w}}$

Thus, the effective flexural stiffness can be calculated provided the moment capacity is known using Eqs. (31) and (32):

$\alpha_{f}=\frac{M_{y}}{\varphi_{y}} \frac{1}{E I_{g}}$

\section{COMPARISONS TO SAMPLED EXPERIMENTAL DATA}

\subsection{Characteristics of the Population of Walls}

A total of 43 wall specimens have been collected [21, 28$36]$ to form a database for evaluating the shear and flexural stiffness prediction models. The experimental data assembled here encompass RC walls subjected to combined quasistatic reversed cyclic loads and axial loads, except where a wall was monotonically loaded by Oesterle et al. [32]. The prime selecting criteria are the provisions of flexural and shear deformations with hysteretic responses. Exceptions comprise five wall tests from Su and Wong [30] and Zhang and Wang [31] which show no shear deformation record, but the walls were tested under high axial loads (ALR $\geq 0.2$ ) which are rare and worthy of examination. The diversity both in geometrics and the standards of compliance are shown in Fig. (5a-b) respectively. The majority - 28 specimens-are rectangular in shape with conventional reinforcement, whereas the others are mainly of barbell-shape and/or have diagonal reinforcement. All of the specimens comply with $\mathrm{ACI} 318, \mathrm{EC} 2$ or EC8, or the Chinese seismic code (GB) with seismic details, except for those specimens 


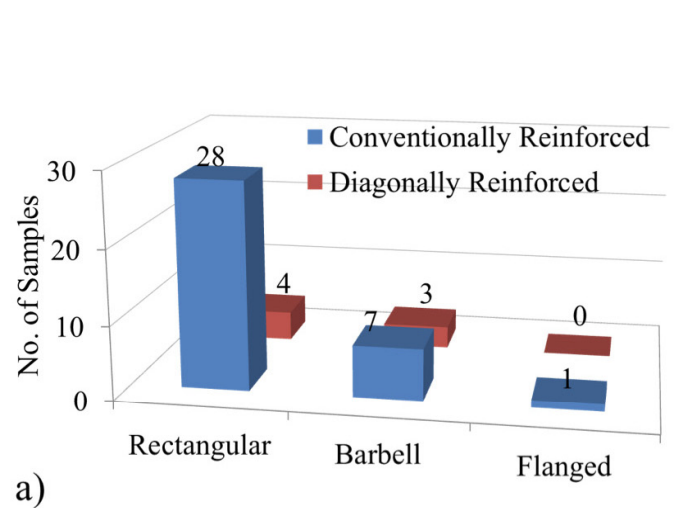

a)

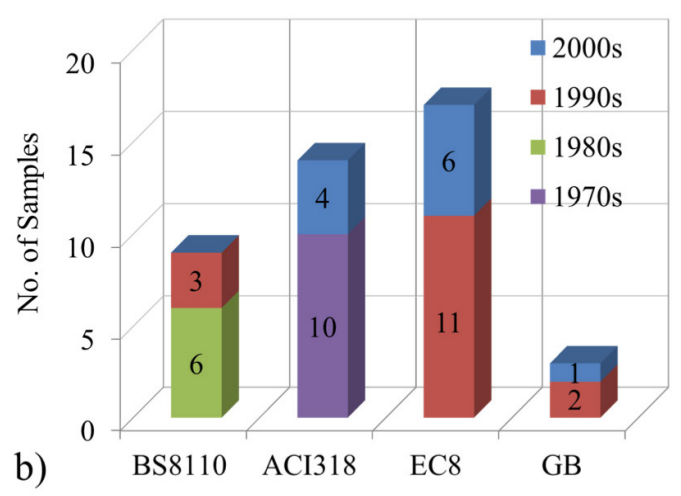

Fig. (5). Characteristics of the population of the walls: (a) sectional shapes, and (b) design codes.

from Oesterle et al. [32], Ho [28] and Su and Wong [30] which are non-seismically detailed. The specimens from the last two references conform to BS8110. Most specimens were designed to yield in flexure except for the squat walls (aspect ratio $\leq 1$ ) tested by Salonikios et al. [21, 34] (shear sliding) and Liu [33] (diagonal tension) which were susceptible to shear failures. The reported failure modes comprise flexural failure, crushing of web or boundary elements, buckling of longitudinal reinforcement and 45 degree diagonal tensile cracks. In view of the scarcity of available data and the complexity of mixed failure modes, the specimens have not been further screened out by the types of failures. For ease of reference, the typical failures for the $\mathrm{RC}$ walls are depicted in Fig. (6a-e).
Table 1 summarises the ranges of characteristics of the collected specimens. The aspect ratios $\left(a_{s}\right)$ range from 0.9 to 3.8. Most specimens have low ALRs from 0 to 0.1 , apart from a few exceptions of 0.2 or higher. Most also consist of normal strength concrete with typical longitudinal $\left(0.4 \% \leq \rho_{s} \leq 2.2 \%\right)$ and transverse $\left(0.3 \% \leq \rho_{s v} \leq 1 \%\right)$ reinforcement ratios. If diagonal reinforcement exists, it is resolved into equivalent longitudinal and transverse steel areas. Most yield strengths $\left(f_{y l}, f_{y v}\right)$ of the reinforcement are between $400 \mathrm{MPa}$ and $600 \mathrm{MPa}$.

\subsection{Comparisons of Effective Shear Stiffness}

Table 2 and Fig. (7) summarise the performance of each effective shear stiffness model discussed in Section 2 by

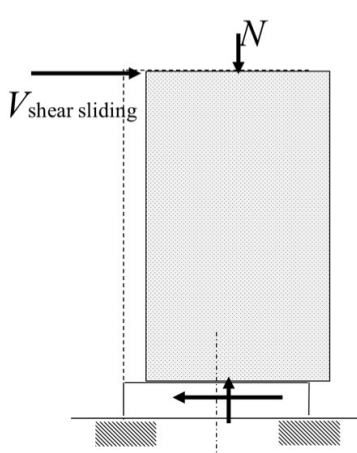

a)

Sliding Shear Failure

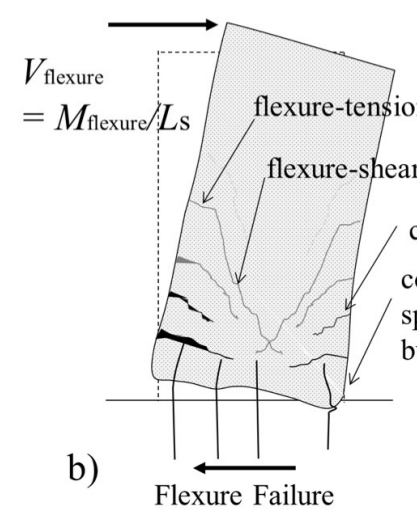

Flexure Failure ion crack

ear crack

cracks close

concrete cover

spalls, steel may

buckle then fracture

c)

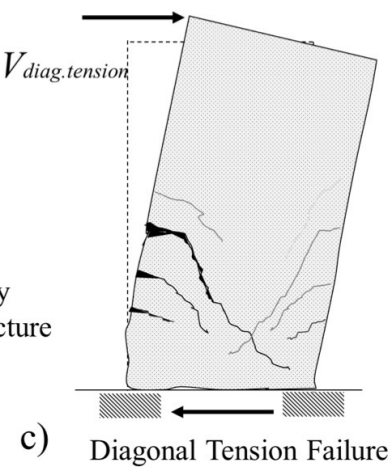

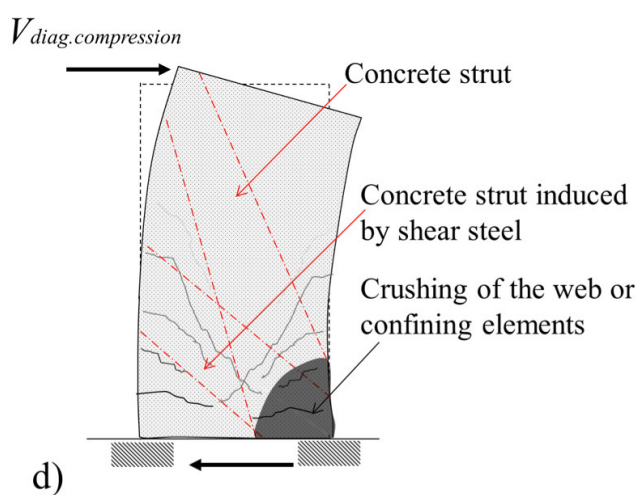

d)

Diagonal Compression Failure

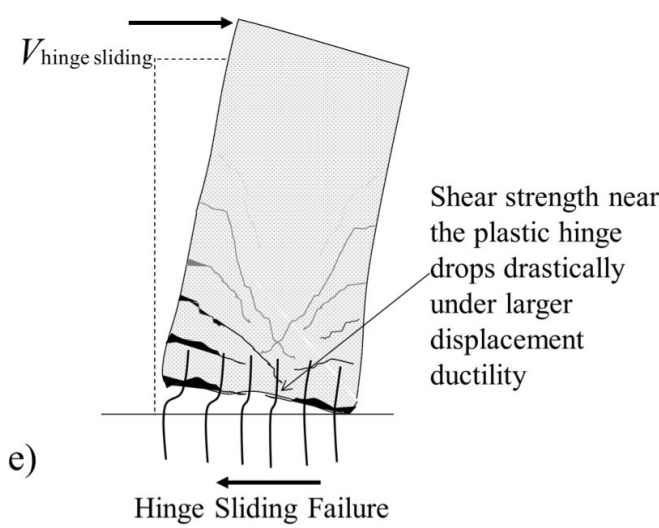

Fig. (6). Typical failure mechanisms of RC walls: (a) shear sliding failure, (b) flexure failure, (c) diagonal tension failure, (d) diagonal compression failure (crushing of web and/or boundary elements), and (e) hinge sliding failure. 
Table 1. Range of data for the wall specimens.

\begin{tabular}{|c|c|c|c|}
\hline Aspect ratio $\left(\mathrm{a}_{\mathrm{s}}=h_{\mathrm{w}} / l_{\mathrm{w}}\right)$ & 3.8 & 0.9 & 1.5 \\
\hline Young's modulus of Concrete, $E_{\mathrm{c}}(\mathrm{Gpa})$ & 44.4 & 19.3 & 25.7 \\
\hline Yield strength of longitudinal steel, $f_{\mathrm{yl}}(\mathrm{Mpa})$ & 596 & 405 & 520 \\
\hline Yield strength of transverse steel, $f_{\mathrm{yv}}(\mathrm{Mpa})$ & 610 & 262 & 520 \\
\hline Axial stress $N / f_{\mathrm{c}}^{\prime} A_{\mathrm{g}}$ & 0.50 & 0.00 & 0.06 \\
\hline Effective shear stiffness reduction factor, $\alpha_{\mathrm{v}}$ & 0.86 & 0.07 & 0.27 \\
\hline Effective flexural stiffness reduction factor, $\alpha_{\mathrm{f}}$ & 0.90 & 0.08 & 0.24 \\
\hline Shear strain ductility, $\mu_{\Upsilon}$ & 5.5 & 1.4 & 3.9 \\
\hline Curvature ductility, $\mu_{\varphi}$ & 32.0 & 2.8 & 7.5 \\
\hline
\end{tabular}

Table 2. Comparisons of predicted and experimental shear stiffness reduction factor $\alpha_{\mathrm{v}}$.

\begin{tabular}{|c|c|c|c|}
\hline References & Mean & Median & $\mathrm{CoV}$ \\
\hline Eurocode 8 (2004) & 2.25 & 1.84 & 0.70 \\
\hline Salonikios (2007) & 1.48 & 1.21 & 0.67 \\
\hline Park and Paulay (1975) & 0.81 & 0.63 & 0.75 \\
\hline Gérin and Adebar (2004) & 0.59 & 0.51 & 0.66 \\
\hline Krolicki et al. (2011) & 0.51 & 0.47 & 0.71 \\
\hline
\end{tabular}

comparing the ratio of the predicted stiffness to the actual stiffness. Without doubt, ACI318 and Eurocode 8 significantly overestimate the stiffness averagely by a factor of 4.5 and 2.25 , respectively. However, $\alpha_{v}=0.5$ proposed by Eurocode 8 is close to the $90^{\text {th }}$ percentile of the sampled specimens (shown in Fig. (7c)); i.e. without alteration, this could still be a conservative estimate for the shear stiffness in walls. Comparatively, Park and Paulay's model provides the best agreement with mean $=0.81$, median $=0.63$ and coefficient of variance $(\mathrm{CoV})=0.75$, whereas Salonikios takes second place with mean $=1.48$, median $=1.21$ and $\mathrm{CoV}=0.67$. The models of Gérin and Adebar, Priestley et $a l$. and Krolicki et al. understate the effective shear stiffness by more than a half. Fig. (7e-f) illustrates the similarities in predictions of the two latter approaches.

Outstanding effective shear stiffness models are discussed in detail below. Fig. (8a-c) compare the predictions of Park and Paulay, Salonikios and Gérin and Adebar with experimental results. The necessary input for prediction is assumed to be the median values shown in Table $\mathbf{1}$ if it is not specified. The controlling parameters for each model are highlighted in these graphs. For brevity, the prediction curves for barbell-shaped walls are not shown but these can easily be determined from the relevant curve by adjusting the shape factor $(f=1)$ and effective depth $(d=1)$ according to the formulations in Section 2. 
a)

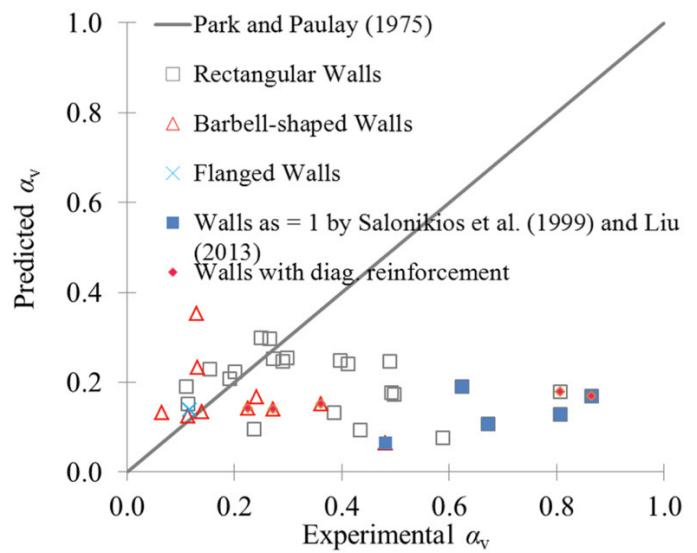

c)

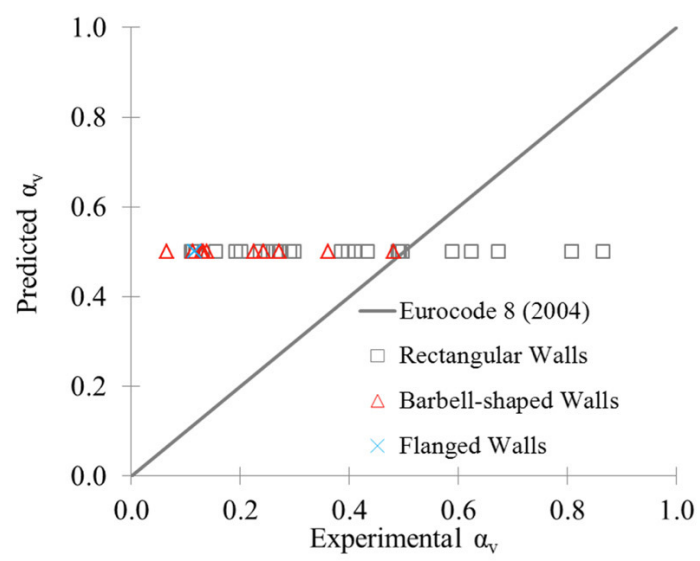

e)

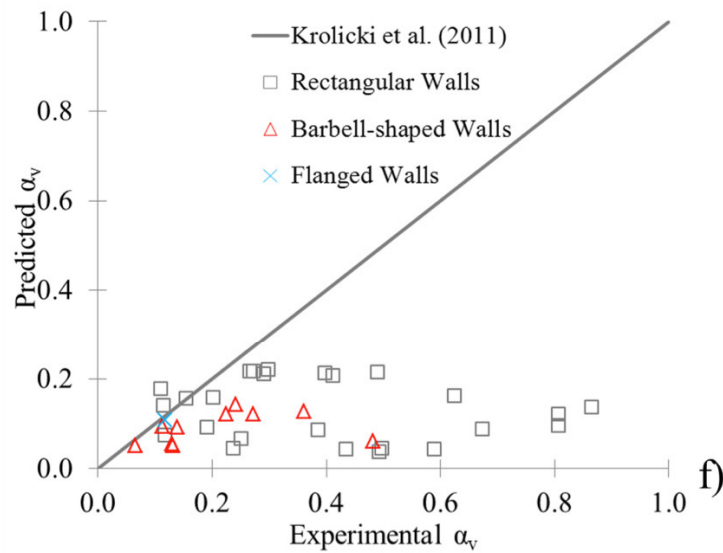

b)

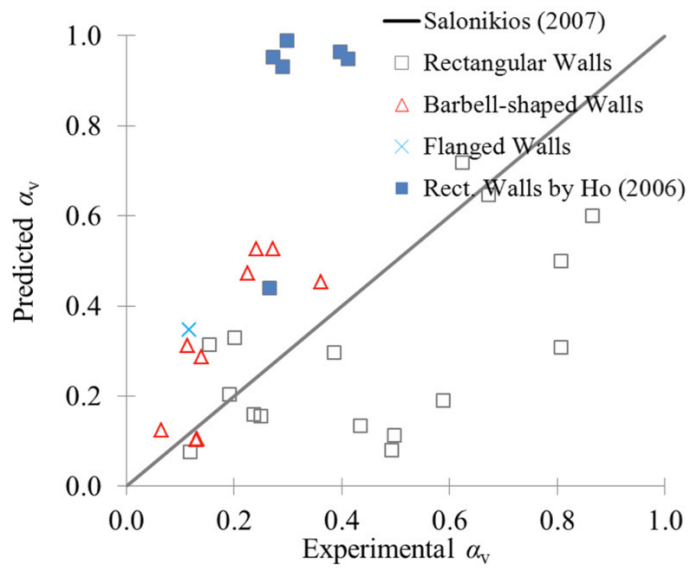

d)
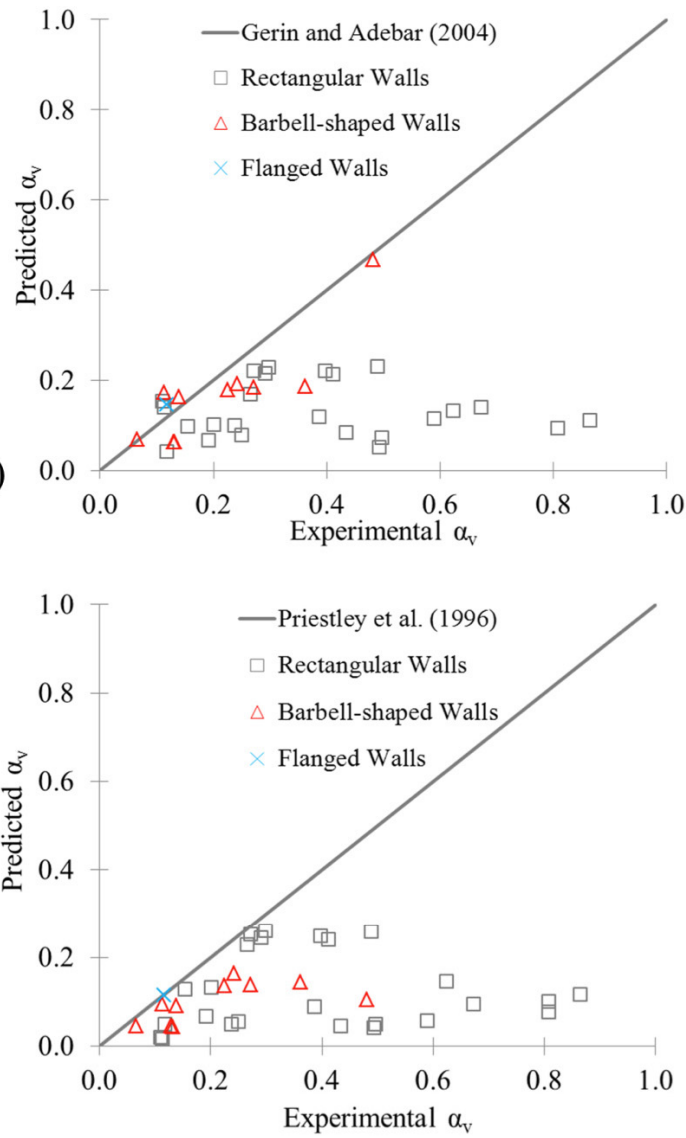

Fig. (7). Variations of predicted shear stiffness to experimental shear stiffness by (a) Park and Paulay (1975), (b) Salonikios (2007), (c) Eurocode 8 (2004), (d) Gérin and Adebar (2004), (e) Krolicki et al. (2011), and (f) Priestley et al. (1996).

Park and Paulay's model suggests an increase in $\alpha_{\mathrm{v}}$ with the shear steel ratios depicted in Fig. (8a). This is in agreement with experimental results of shear steel ratios between $0.5 \%$ and $1.1 \%$, despite the scattering for steel ratios being< $0.5 \%$. If the specimens with pre-emptive shear failures prior to reaching their flexural strength are ignored (low-rise squat walls by Salonikios (shear sliding) and Liu (diagonal tension)), the prediction by Park and Paulay improves to mean $=0.91$, median $=0.85$ and $\mathrm{CoV}=0.65$. This indicates that Park and Paulay's model is more appropriate for walls designed to yield in flexure. The model also shows a tendency to understate the effective shear stiffness for diagonally reinforced specimens. When the diagonally reinforced specimens (Salonikios, Shaingchin et al.) are also ignored, the prediction can further be improved to mean $=0.99$, median $=0.94$ and $\mathrm{CoV}=0.62$. These two deficiencies are not unexpected due to the omissions of these effects in the truss analogy model.

Fig. (8b) indicates the good match of Salonikios's prediction to his own dataset. However, for squat walls that yield in flexural mode (Ho's specimens) and slender walls (aspect ratios $\geq 1.5$ ), it tends to overestimate the shear stiffness by more than double. The extensive softening in shear for squat walls presented by Ho [28] compared to Salonikios et al. $[21,34]$ could be attributed to the following: (a) Ho's specimens are non-seismically detailed; and (b) they are designed 
a)
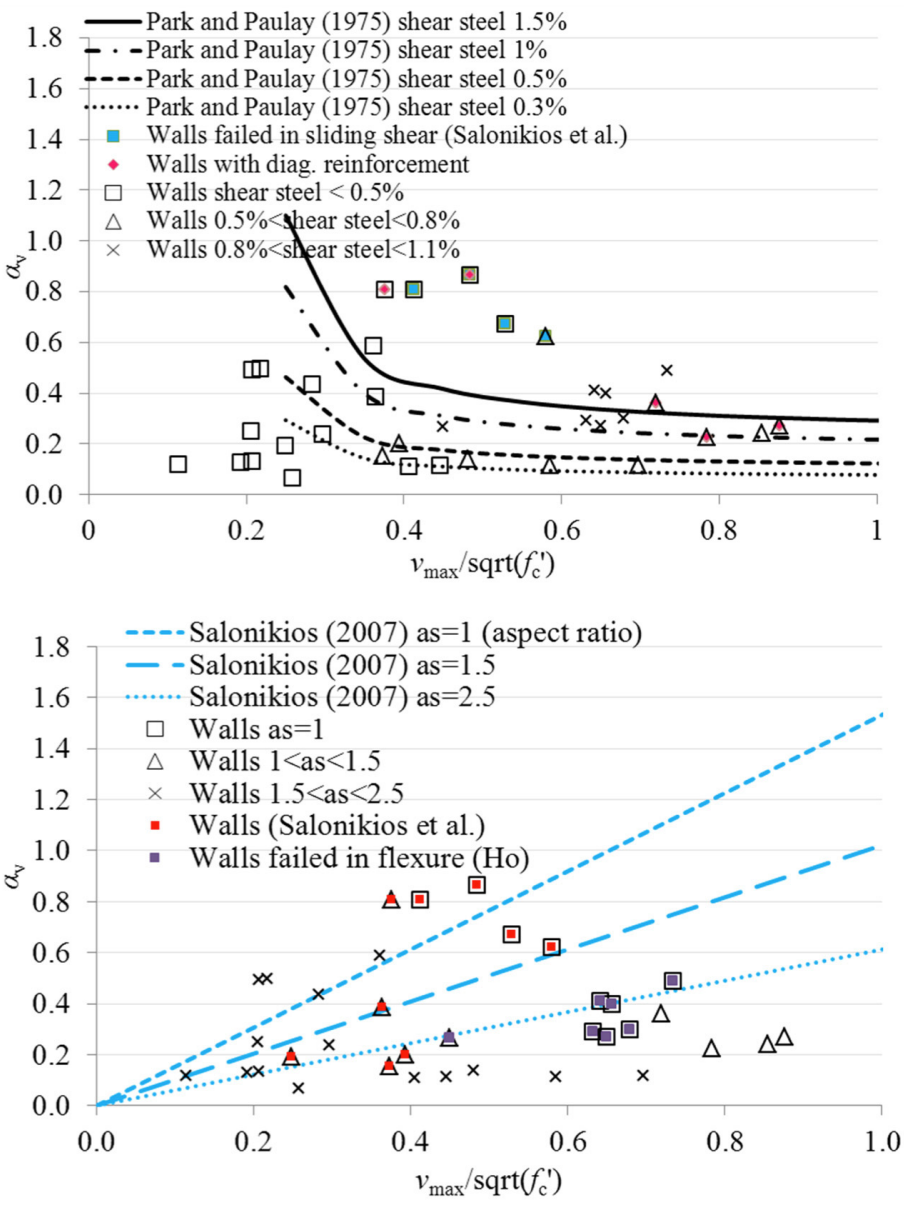

b)

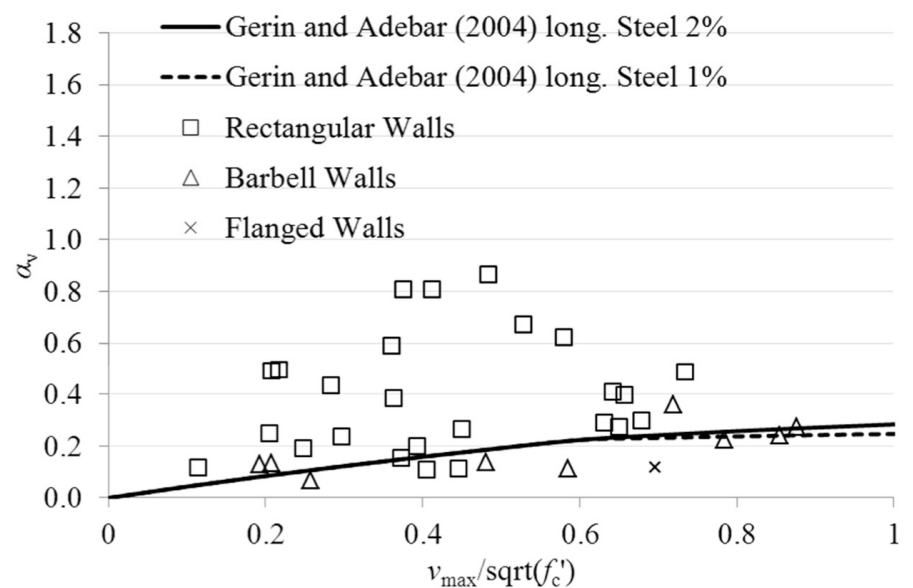

Fig. (8). Variations of shear stiffness against the normalised shear strength for (a) the Park and Paulay (1975) model, (b) the Salonikios (2007) model, and (c) the Gérin and Adebar (2004) model.

to fail in flexure, whereas Salonikios's low-rise specimens are susceptible to shear sliding failure. This indicates the pronounced effect of flexural cracks in reducing shear stiffness, as well as the limited reduction in the shear stiffness by pre-emptive shear sliding failure localised at the base of the wall.

Comparatively, the model of Gérin and Adebar understates the effective shear stiffness for most of the walls by half; see Fig. (7d). However, the model yields supreme results when only barbell-shaped walls and flanged walls are considered - mean $=0.88$, median $=0.80$ and $\mathrm{CoV}=0.39-$ as shown in Fig. (7d) and Fig. (8c) which depict the predicted shear stiffness against the normalised shear strength. A possible explanation for this is the likelihood of shear steel yielding in barbell-shaped and flanged specimens with enhanced moment capacities due to a higher moment of inertia. Over three quarters of these specimens failed by web crushing or buckling of longitudinal reinforcement. The buckling of reinforcement is usually accompanied by spalling of concrete cover and yielding of transverse steel. Further evidence is that the shear stress demand on the truss mechanism $\left(v_{\max }-v_{\mathrm{c}}\right)$ is close to the shear steel capacity $\left(\rho_{\mathrm{sv}} f_{\mathrm{yv}}\right)$ for these 
specimens. All of the aforementioned evidence supports the assumption of transverse steel yielding in deriving the model. The Gérin and Adebar model yields reasonable lower-bound shear stiffness for rectangular wall specimens due to the assumptions of shear steel yielding and fully cracked wall sections along the height.

\subsection{Comparisons on Shear Strain Ductility}

The ultimate shear strain for shear dominated elements is controlled by two types of concrete failures: brittle compression failure and relatively ductile shear failure [10]. For heavily reinforced elements subjected to high shear stress, the former is likely to occur, which can be attributed to exceeding the diagonal compression strength of concrete with reduction due to transverse tensile strains. The latter failure mode is associated with large shear deformation along the cracks resulting from excessive local damage such as concrete splitting and crushing around the reinforcement.

FEMA356 [6] generalises the force-displacement curve by including uncracked stiffness up to the yield strength. Then, the strength remains constant to the point of ultimate shear strain equal to 0.0075 followed by rapid degradation to 0.4 of the peak strength. By assuming the shear strain at yield is equal to 0.0025 [Eq. (5.2) of 18], this implies a shear strain ductility $\left(\mu_{\gamma}\right)$ of 3 . For both the USCD approach [15, 37] and the modified USCD by Krolicki et al. [16], the shear strength envelope declines drastically for displacement ductility $>2$ (controlled by $\gamma_{p}$ ). If the wall fails in the shear mode, the shear strain ductility for $V=0.8 V_{\max }$ can be estimated as $3.45[15,37]$ or 3 [16]. Since the shear to flexural deformation ratio is assumed to be constant after yielding, the shear strain ductility is equal to the displacement ductility. Hence, these lower-bound estimates of shear strain ductility coincide with FEMA356. For walls that yield in flexure, the displacement ductility could be larger and this depends on the ultimate displacement, which is usually defined by the intercepting displacement of the shear and flexural strength envelopes. In extreme cases, the ultimate displacement ductility for walls over-reinforced in shear is solely dictated by the degradation of the flexural strength envelope.

Alternatively, based on the cracked shear strain formulated in Eq. (27) and 21 large-scale membrane element tests, Gérin and Adebar [10] recommend using:

$\mu_{\gamma}=4-12 \frac{v_{\max }}{f_{c}{ }^{\prime}}$ for $\frac{v_{\max }}{f_{c}{ }^{\prime}} \leq 0.25$

The shear stress limit of $0.25 f_{\mathrm{c}}$ ' is adopted from the shear strength study by Collins et al. [38], to avoid concrete compression failure.

The prediction models for shear strain ductility of Gérin and Adebar, UCSD, Krolicki et al. and FEMA356 are compared in Fig. (9). Gérin and Adebar's model provides a reasonably good lower-bound prediction of the shear strain ductility demands, whereas other models suggest only a constant shear strain ductility of 3 and 3.45 . These coincide with the predictions by Gérin and Adebar when normalised shear strength $\left(v_{\max } / \sqrt{ }\left(f_{c}^{\prime}\right)\right) \approx 0.5$. For walls susceptible to the shear sliding failure presented by Salonikios, the shear strain ductility could be reduced to only half of the predicted limit.

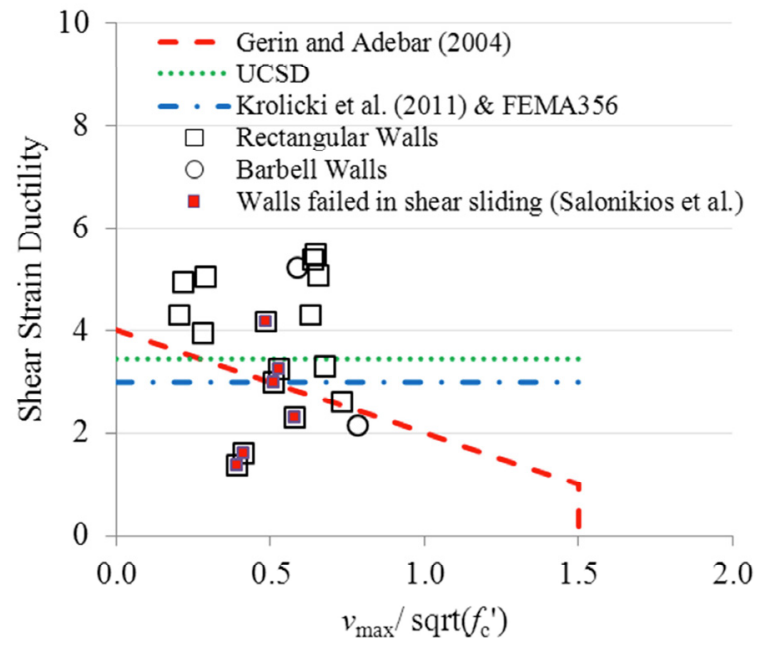

Fig. (9). Variations of shear strain ductility against the normalised shear strength.

\subsection{Comparisons of Effective Flexural Stiffness}

The ratios of predicted to experimental flexural stiffness at the yield state for different approaches are summarised in Table 3. The uncracked stiffnesses recommended by ASCE41-06, FEMA356 $\left(\alpha_{f}=0.8\right)$ and ACI318-11 $\left(\alpha_{f}=0.7\right)$ overstate the stiffness by a factor of 3 or more, whereas stiffnesses suggested in Eurocode 8 or the cracked walls in ASCE41-06, FEMA356 $\left(\alpha_{f}=0.5\right)$ andACI318-11 $\left(\alpha_{f}=0.35\right)$ provide a closer estimate; however, they still overstate the stiffness on average by a factor of 2 and 1.5, respectively. The upper and lower-bound stiffness models suggested by Adebar et al., adopted in the latest CSA [9], share similar behaviours but the lower-bound model provides a better estimation by overstating only $30 \%$. As for the Ahmad implicit method and the Priestley and Kowalsky model, they are capable of predicting the actual flexural stiffness with slight overestimation: mean errors within $20 \%$, median errors within $5 \%$ and $\mathrm{CoVs}$ of around 0.35 . On the other hand, Bachmann's model shows comparable capability with slight underestimation of the stiffness, at around $10 \%$. Yet, the simplicity of the calculation in the Priestley and Kowalsky model and the Bachmann model should be appraised, particularly the latter which requires only the ALR and longitudinal steel ratio as inputs.

Graphical presentations for some of these methods, comprising the Bechmann, Priestley and Kowalsky models, lower and upper-bound estimates by Adebar et al., Eq. (10-8) in ACI318-11 and the Ahmad implicit method, are depicted in Fig. (10). Despite the complexity of the calculations, Ahmad's implicit method allows a close approximation for flexural stiffness of walls $\left(\alpha_{f} \approx 0.8\right)$ under high ALRs $(=0.25$ to 0.5 , tested by $\mathrm{Su}$ and Wong [30], Zhang and Wang [31]).

The experimental effective stiffness demonstrates less deviation in flexural stiffness models compared to those in shear stiffness models, which is reflected in the smaller CoVs and less scattering plots shown in Fig. (10). This implies that those developed flexural models, either by classical mechanics with empirical observations (e.g., Priestley and Kowalsky, 1998) or by a parametrically determined model 
Table 3. Comparisons of predicted and experimental flexural stiffness reduction factor $\alpha_{f}$.

\begin{tabular}{|c|c|c|c|}
\hline \multicolumn{4}{|c|}{ Comparison on Pred. $\alpha_{f} /$ Exp. $\alpha_{f}$} \\
\hline uncracked walls for ACI318 (2011) & 2.95 & 2.93 & 0.53 \\
\hline Adebar et al. (2007) upper-bound & 2.74 & 2.62 & 0.47 \\
\hline Eq. $(10-8)$ in ACI318 (2011) & 1.59 & 1.54 & 0.45 \\
\hline cracked walls for ACI318 (2011) & 1.47 & 1.46 & 0.53 \\
\hline Adebar et al. (2007) lower-bound & 1.32 & 1.30 & 0.45 \\
\hline Ahmad (2011) Implicit Method $I_{\text {eff }}$ & 1.18 & 1.05 & 0.35 \\
\hline Ahmad (2011) Implicit Method $I_{\mathrm{cr}}$ & 0.78 & 0.73 & 0.41 \\
\hline
\end{tabular}

(e.g., Ahmad's implicit model), can satisfactorily capture the actual behaviour. It could also be attributed to design philosophy which usually requires shear walls to be designed to yield in flexure.

Fig. (11a) depicts the effective flexural stiffness of walls against the ALRs estimated by the Bechmann and Adebar et al. models. The upper and lower-bound stiffnesses estimated by the Adebar et al. model effectively encompass the test data collected, whereas the prediction by Bachmann is capable of estimating the mean effective stiffness even for walls under high ALRs $(\geq 0.2)$. For the gradient of $\alpha_{f}$ against ALR, a distinctive difference between the experimental results and the lower-bound stiffness suggested by Adebar et al. is observed. This difference is prominent when ALR $\geq 0.2$, and $\alpha_{f}$ could possibly reach 0.8 or higher in the presence of extremely high ALRs $(\geq 0.4)$. This agrees with the speculation by Adebar et al. [7] that the lower-bound stiffness could possibly be raised to account for a reduction in cracks under high axial loads.

Fig. (11b) depicts the variations of effective flexural stiffness against normalised moments $\left(M_{\max } /\left(b l_{w}^{2} f_{c}{ }^{\prime}\right)\right)$ for the Priestley and Kowalsky model. For barbell-shaped and flanged walls, equivalent rectangular sections with the same $I_{g}$ are derived for estimating $b l_{\mathrm{w}}{ }^{2}$. The underlying assumption in Priestley and Kowalsky's model is that the yield curvature is almost constant and is independent of longitudinal steel ratios, i.e. the moment and flexural stiffness are directly proportional to each another. This concept has gained prominence since its introduction and is well explained in Fig. (11b). The specimens with higher yield strengths for longitudinal steel would result to higher yield strains and yield curvatures, thus they tend to have lower effective flexural stiffness, provided the moment capacity is the same. The close approximations to experimental yield curvatures, which are shown in Fig. (12a), further validate the yield curvature formulation proposed by Priestley and Kowalsky.

\subsection{Comparisons of Curvature Ductility}

Fig. (12b) depicts the curvature ductility $\left(\mu_{\varphi}\right)$ of the collected specimens. As the hysteretic responses of some specimens might not record a significant drop in post-peak shear strength, difficulty occurs in defining the ultimate curvature. Thus, a considerable number of samples are excluded here particularly for ductile structural walls. For other walls, the experimental curvature ductilities are compared to the predictions by Priestley and Kowalsky [27]. Based on the moment-curvature analyses on rectangular walls, they proposed:

Serviceability limit state: $\mu_{\varphi}=\frac{0.0174}{2 \varepsilon_{y l}}$

Ultimate limit state: $\mu_{\varphi}=\frac{0.072}{2 \varepsilon_{y l}}$

where $\varepsilon_{y l}$ denotes the yield strain of the longitudinal reinforcement.

For walls lacking seismic details or which failed in shear sliding, the curvature ductility could be reduced to the serviceability limit proposed by Priestley and Kowalsky, whereas few walls complying with codes that have seismic details (ACI1977, GB) have exceptionally low curvature ductility. Yet, a conclusion to the under-performance of detailing by these provisions cannot be directly drawn due to limited test data. Besides the influence by design philosophy, the increase in ALR drastically reduces the curvature ductility, particularly for $A L R \geq 0.2$.

\section{RECOMMENDATION ON THE EFFECTIVE STIFFNESS OF WALLS FOR MODELLING}

\subsection{Shear Stiffness}

In the case of seismic analyses, expected stiffness should be adopted for design [(cl. 8.8.2) in 3, 9, 15]. For wall 
a)

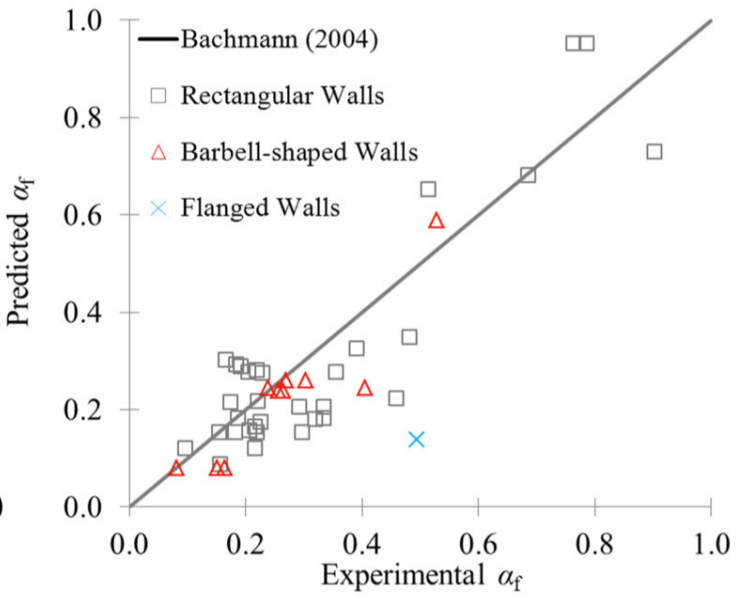

c)

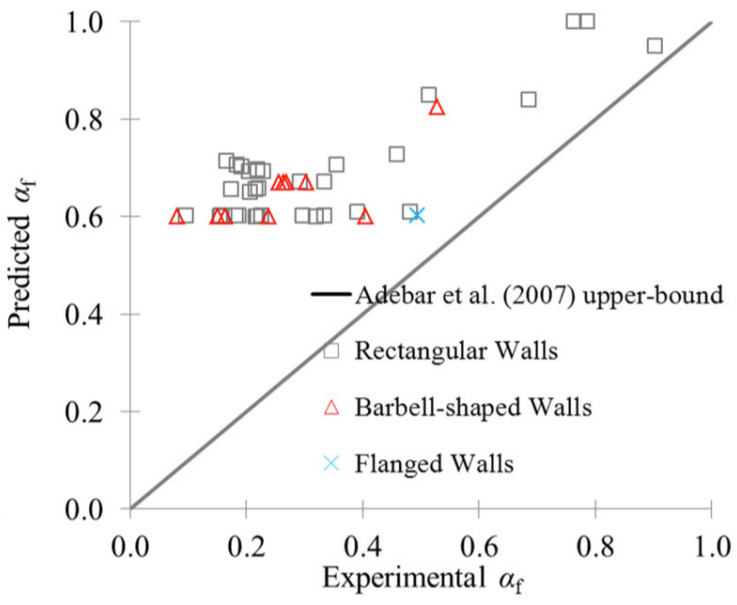

e)

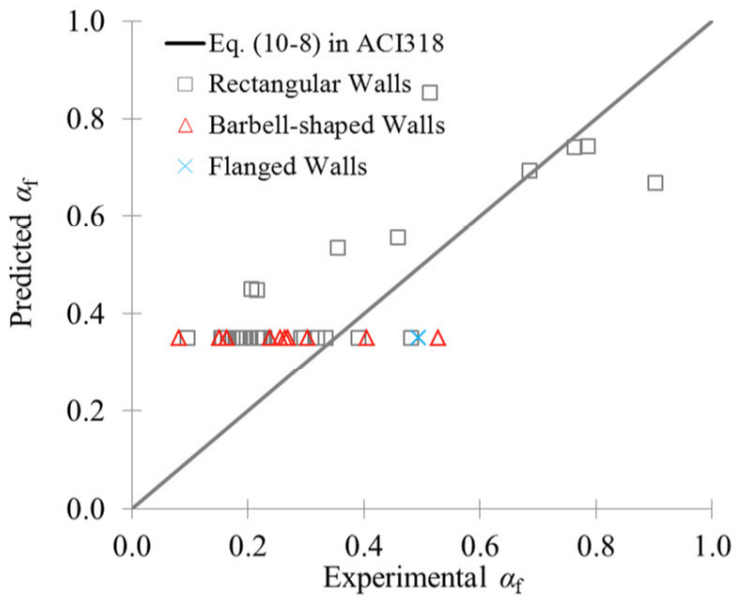

b)

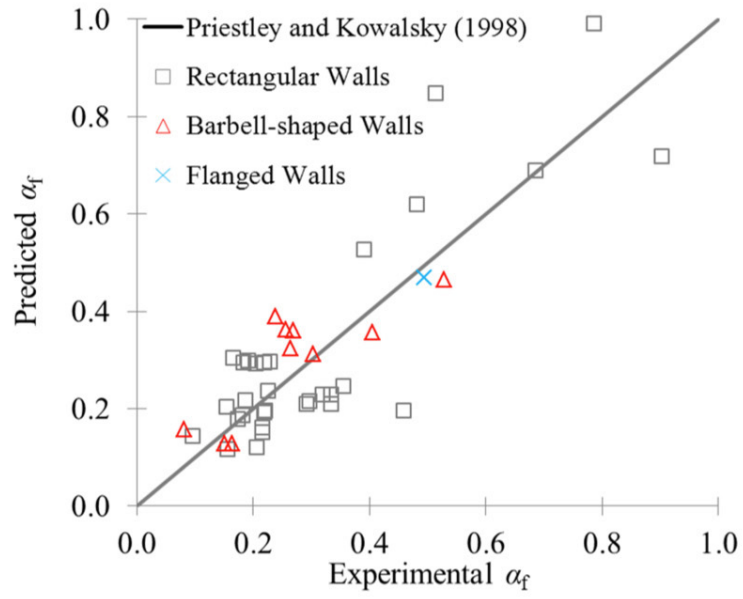

d)
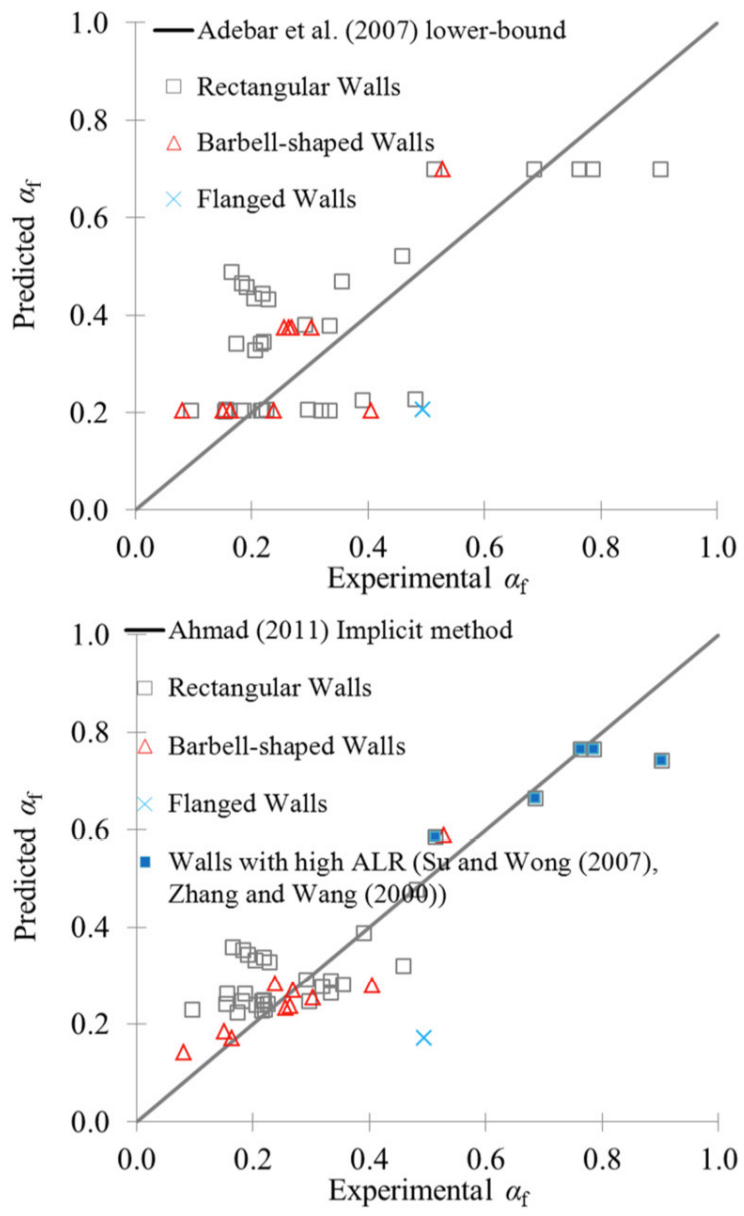

Fig. (10). Variations of predicted flexural stiffness to experimental flexural stiffness by (a) Bachmann (2004), (b) Priestley and Kowalsky (1998), (c) Adebar et al. (2007) upper-bound, (d) Adebar et al. (2007) lower-bound, (e) Eq. (10-8) in ACI318 (2011), and (f) the Ahmad (2011) implicit method.

members being fully loaded to flexural capacity, a mean effective shear stiffness of 0.3 can be reasonably assumed for walls designed to yield in flexure. For partly loaded walls $\left(M>M_{c r}\right)$, shear stiffness deteriorates with the onset of flexural cracks. An upper-bound stiffness of 0.5 , consistent with Eurocode 8, may be an appropriate option and can generally be applied to all walls under MCE level. More precise prediction models are also available: (a) the Gérin and Adebar model can be adopted when shear steel yielding is antici- pated; (b) the Park and Paulay model allows a good approximation for walls that fail in flexure with or without seismic details; whereas (c) the Salonikios model fits better for squat walls that are susceptible to shear sliding failures and walls with diagonal reinforcement. Fig. (13a) and (13b) summarise the performances of the last two models by categorising the specimens into various design philosophies. Yet, the significant scattering for the latter model could indicate that certain controlling parameters are not well accounted for. 

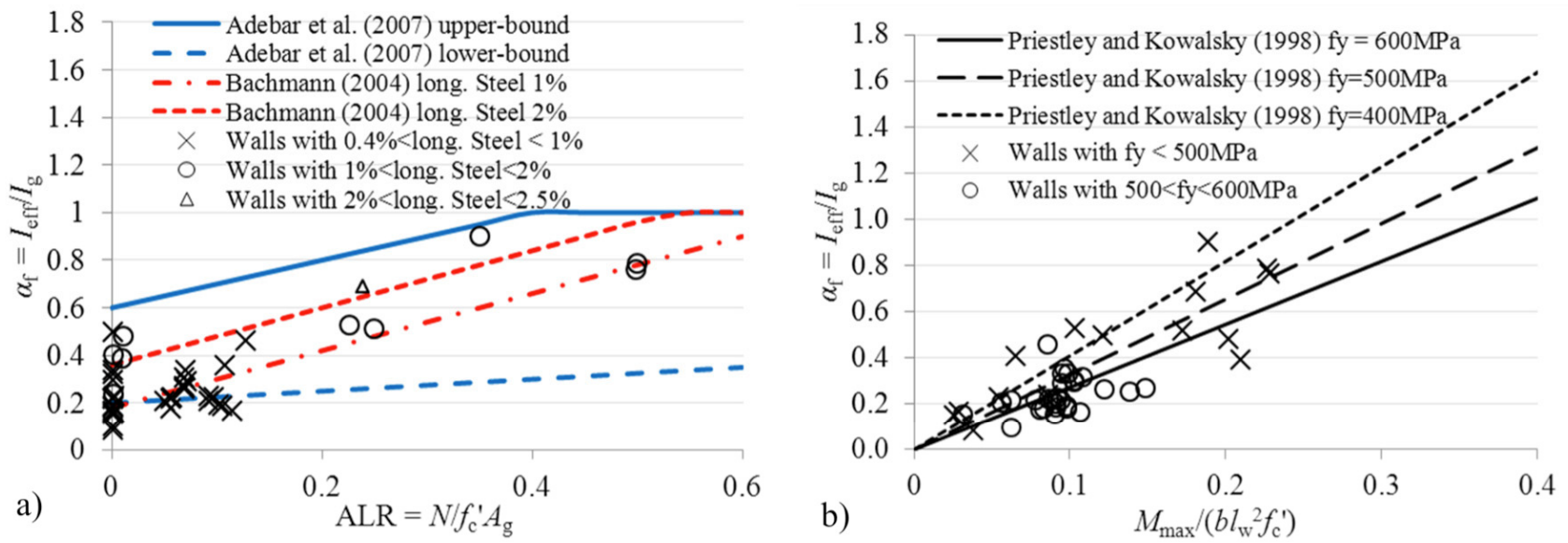

Fig. (11). Variations of flexural stiffness against the (a) ALRs for Adebar et al. (2007) and Bachmann (2004) models, and (b) normalised moment capacity for the Priestley and Kowalsky (1998) model.
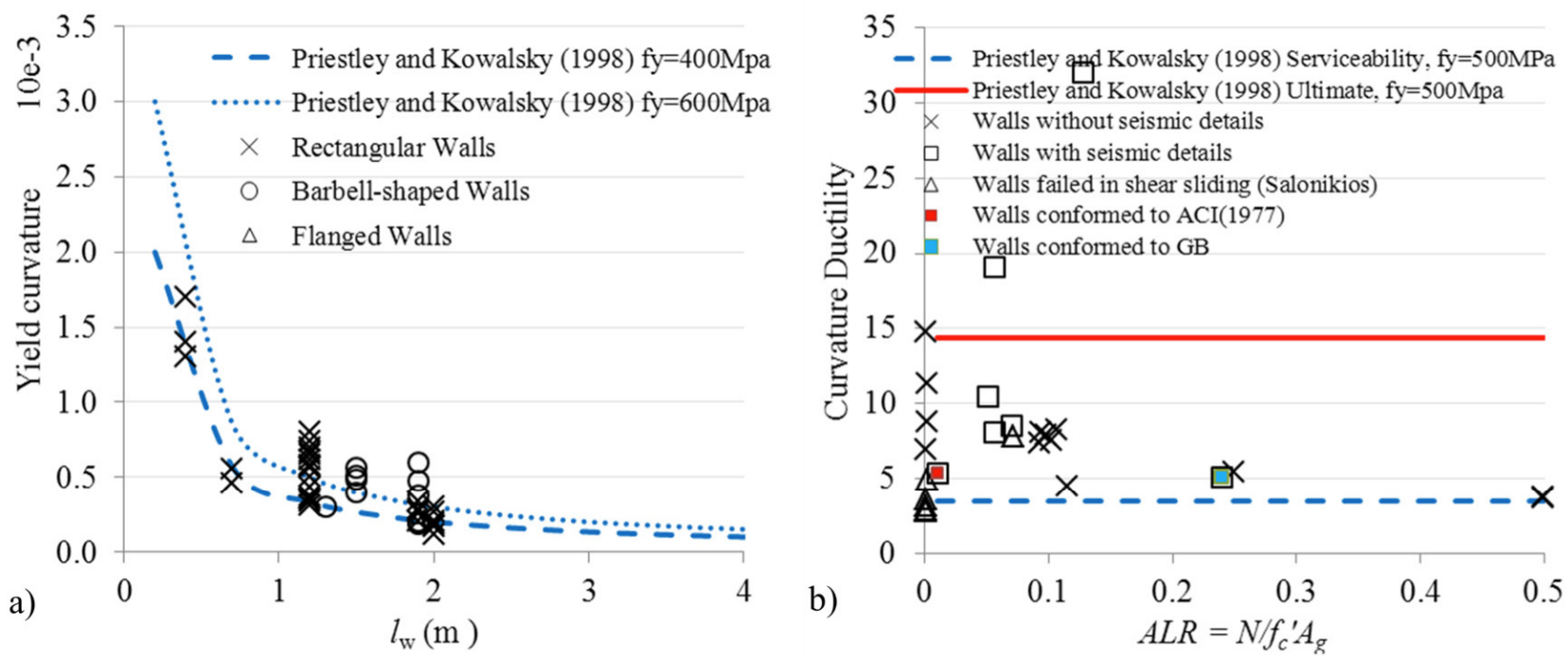

Fig. (12). Variations of (a) the yield curvature against the wall length, and (b) the curvature ductility against the ALR for the Priestley and Kowalsky (1998) model.

As for the secant shear stiffness at the ultimate state, this can be determined by dividing the effective shear stiffness with the shear strain ductility, for which a lower-bound estimate of 3 can be conservatively assumed if the shear sliding failure is prevented. However, if the wall is subjected to high shear stress demands $\left(v_{\max } / \sqrt{ }\left(f_{c}{ }^{\prime}\right) \geq 0.5\right)$, then one may follow the prediction of the Gérin and Adebar model.

\subsection{Flexural Stiffness}

In general, the codified flexural stiffness for either uncracked or cracked walls overstates the effective flexural stiffness of walls at the yield state. Among these, the lowerbound estimate following the Adebar et al. model, adopted in CSA, provides the best estimate by overstating only $30 \%$ on average.

In addition, other readily available flexural models by researchers like Bachmann, and Priestley and Kowalsky can be considered useful for practical purposes. The former model requires only the ALR and longitudinal steel ratio as input, whereas the latter model depends on the moment capacity and yield strain of longitudinal steel. In the case of high-rise shear walls subjected to large ALRs ( $\geq 0.2)$, Ahmad's implicit method could serve as a verification tool. Despite its complexity and the requirement for more input parameters, such as applied moment and axial loads, it shows superiority in its application to walls under high axial loads in comparison to both the Bachmann model and the Priestley and Kowalsky model. The performances of these models are also summarised in Fig. (13c-f).

\subsection{Limitations and Further Studies}

The primary limitation of this study is the paucity of wall tests with shear deformation history included. Despite the pronounced relationships revealed by a small batch of specimens, some adverse effects which require further indepth study encompass:

a) For walls that yield in mechanisms other than flexure (e.g. shear sliding, diagonal compression, anchorage failure), their influences on effective shear stiffness and shear strain ductility could be tremendous. For instance, 
a)

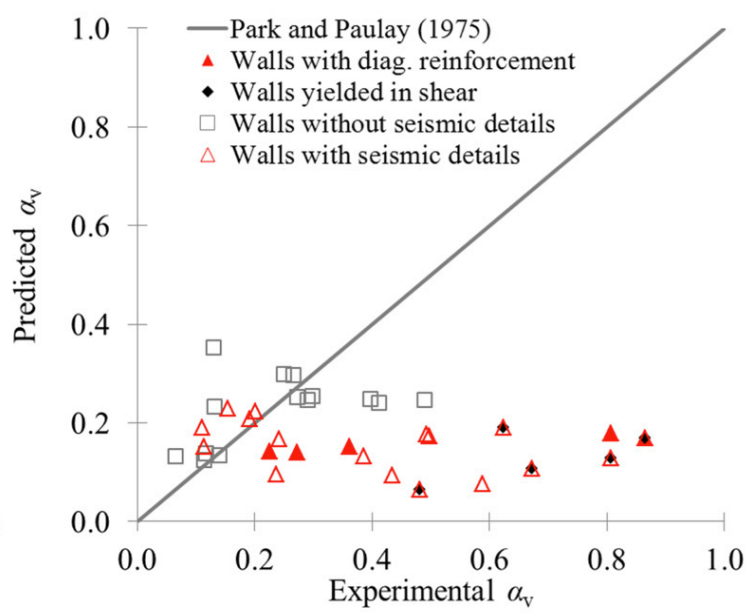

c)

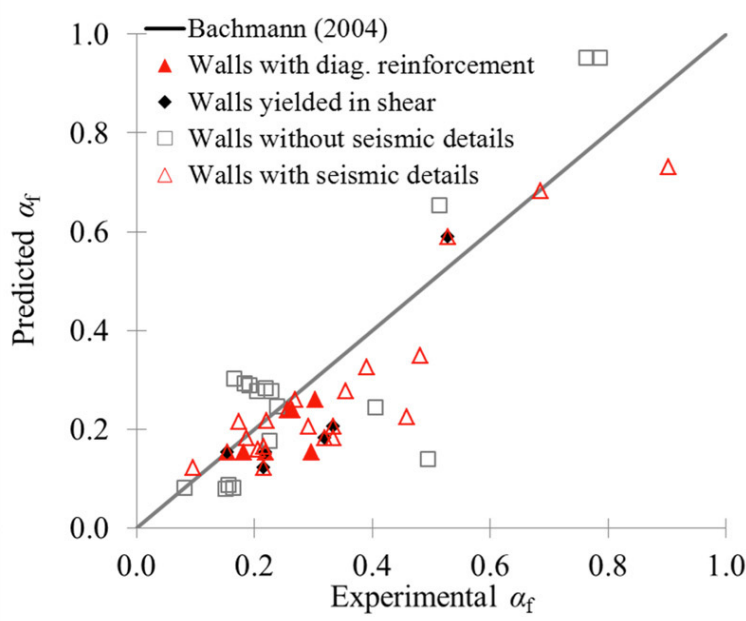

e)

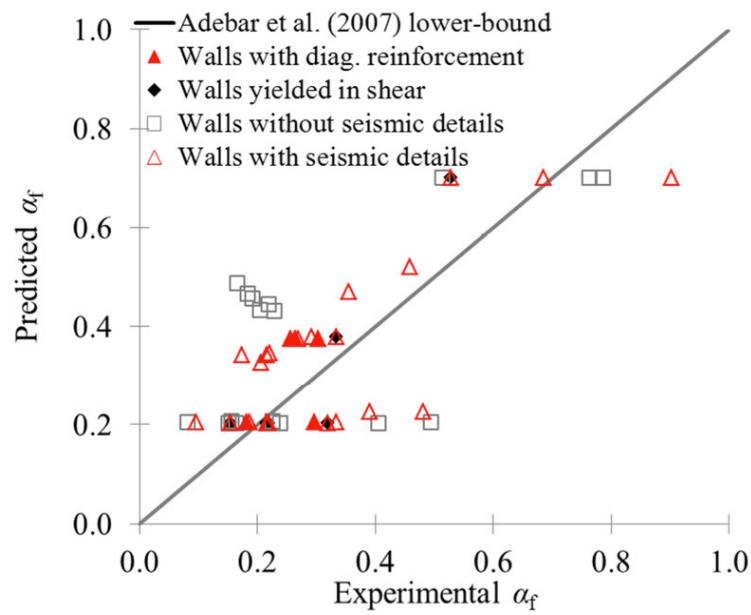

b)

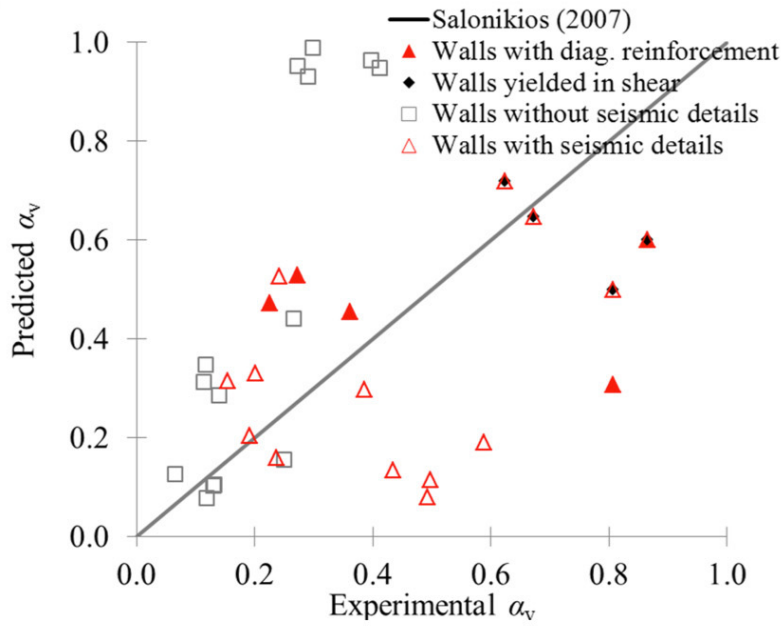

d)
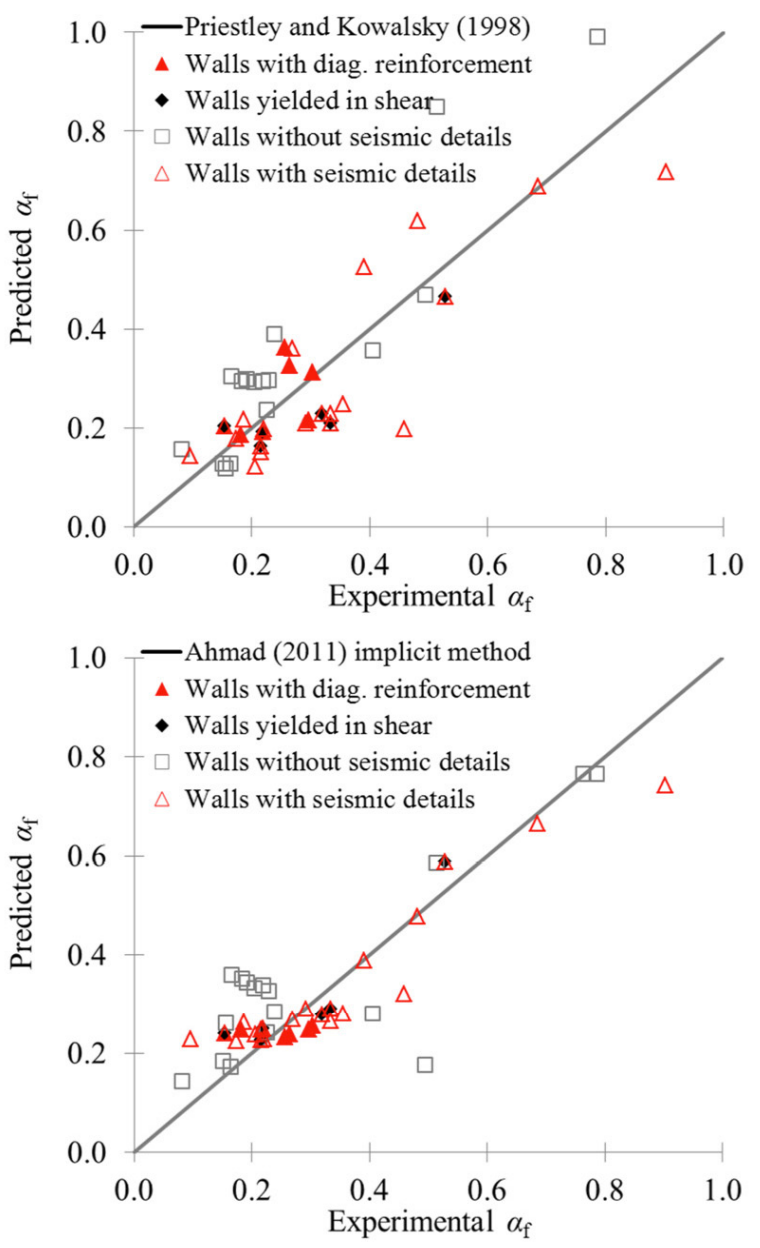

Fig. (13). Summary of predicted effective stiffness compared to experimental stiffness under various design philosophies: Shear stiffness models by (a) Park and Paulay (1975), (b) Salonikios (2007); flexural stiffness models by (c) Bachmann (2004), (d) Priestley and Kowalsky (1998), (e) Adebar et al. (2007) lower-bound, and (f) the Ahmad (2011) implicit method.

specimens that yielded in shear sliding by Salonikios et al. exhibited high shear stiffness and low shear strain ductility. These studies are vital especially for nonseismically detailed walls, as their yielding mechanisms under MCE are not properly controlled.

b) The consequences of high ALRs $(\geq 0.2)$ on the effective shear stiffness, and the possible reduction of the curvature and shear strain ductility. c) Diagonally reinforced low-rise squat walls exhibit increased effective shear stiffness.

d) Sliding shear deformation localised at the plastic hinge region also contributes to overall deformation. Some experiments might not distinguish this from the general shear deformation. Although its contribution is relatively trivial at the yield state, e.g. Salonikios [34], for more precise analyses, its effect on the softening of the effec- 
tive stiffness should be accounted for, particularly for the ultimate state of squat walls (which could attribute to $20 \%$ or more of the total deformation).

Quantifications of the aforementioned effects remain difficult due to the lack of suitable wall data. Most of the collected test data are from walls with low ALRs and that yielded in flexure.

RC walls subjected to seismic loads could exhibit different hysteresis loops due to the load-rate dependent strength and stiffness degradations. Dynamic tests allowing derivations of effective shear and flexural stiffnesses are summarised here: Daniel et al. [36] tested two 6-storey RC walls using 1940 El Centro and 1971 Pacoima Dam earthquake ground motions, of which the walls at ground level exhibited an $\alpha_{\mathrm{f}}=0.4$ to 0.5 and an $\alpha_{\mathrm{v}}=0.1$; Carrillo and Alcocer [39] compare the hysteresis loops between wall specimens under cyclic or dynamic loads. Despite higher strength and stiffness degradation rates revealed in the dynamic tests, the differences are within $10 \%$ to $30 \%$ in the maximum shear strength and the drift ratio at peak load. For the two normal strength concrete wall specimens, they exhibited an $\alpha_{\mathrm{f}}=0.3$ to 0.4 and an $\alpha_{\mathrm{v}}=0.2$ under the dynamic test. Compared to the analytical models, Gerin and Adebar's shear model (mean predicted $\alpha_{\mathrm{v}} /$ measured $\alpha_{\mathrm{v}}=1.14$ ) and Bachmann's flexural model (mean predicted $\alpha_{\mathrm{f}} /$ measured $\alpha_{\mathrm{f}}=0.88$ ) outperform the others for the four experiments above. Though more test data are required to reach a conclusion, the analytical models appear to maintain a reasonable accuracy for walls under seismic loads.

Besides, the studies for effective stiffnesses are not limited to shear walls. It is more complicated for masonry infilled frames with or without perforations, which are not well discussed in most of the standards. Continuous research has been devoted to it, like Kakaletsis [40] has summarised the yield rotations of infilled frames from experiments which shows possibility in determining the yield stiffness provided the shear strength at yield can be correctly derived.

\section{CONCLUSION}

The adoption of a suitable effective stiffness is crucial in any seismic analyses, particularly the equivalent lateral force method and response spectrum analysis [41] which nonlinear properties of the RC members are usually not implicitly accounted for in the material constitution of the numerical model. Thus, engineers have to make a suitable judgement on reducing the stiffness accordingly. Accurate predictions of effective stiffnesses for shear walls at the yield state are vital to seismic analyses primarily in three aspects: (a) accurate loading distribution among elements, (b) determination of the sequences of mechanisms, (c) determination of the ultimate deformation capacity if the ductility capacity is prescribed by codes, e.g. New Zealand Standards (cl.2.2, cl.4.3) [42] and Eurocode 8(c1.5.2.2.2) [4]. The use of codified effective stiffnesses could render structures over stiff. For instance, the natural period of a single-degree-of-freedom can be simply expressed as $2 \pi \sqrt{ }$ (mass/stiffness). For sheardeformation dominated walls, use of intact shear stiffness following ACI318-11 or a 0.5 stiffness reduction factor following EC8 could result in underestimating the period at yield by $55 \%$ or $37 \%$ respectively, provided the measured shear stiffness reduction factor could be as low as 0.2 at yield. It leads to over-conservative design in forces and underestimation of the deformation demands, indicating the imperative of reviewing effective stiffness models of walls.

Effective flexural and shear stiffness models proposed by various researchers and codified references have been compared in this study. Those models are verified against 43 collected wall tests mainly subjected to reverse-cyclic loads. It is found that most of the stipulated stiffnesses have been over-conservative, particularly for the use of gross shear stiffness when flexural cracks have occurred, which can result in overstating the stiffness by a factor of 4 . Yet, there exists simplified estimations which yield appropriate results, e.g. shear stiffness models by Park and Paulay, and Salonikios based on classical truss analogy and Gérin and Adebar's model based on Mohr's circle model. Outstanding flexural stiffness models comprise the Bachmann model, the Priestley and Kowalsky model and Ahmad's implicit method, the latter of which is relatively complicated but more precise for walls under high axial loads. Due to a paucity of test data, quantification of adverse influences on the effective shear stiffness, curvature and shear strain ductility by higher ALRs and yielding mechanisms other than flexure remain significant topics for further studies.

\section{CONFLICT OF INTEREST}

The authors confirm that this article content has no conflict of interest.

\section{ACKNOWLEDGEMENTS}

Declared none.

\section{REFERENCES}

[1] ASCE, "Seismic Rehabilitation of Existing Buildings, ASCE/SEI 41-06", American Society of Civil Engineers, Reston, Virginia, 2007.

[2] Pacific Earthquake Engineering Research Center (2010). "Guidelines for Performance-Based Seismic Design of Tall Buildings", PEER Report 2010/05, prepared by the TBI Guidelines Working Group, Berkeley, California, 2010.

[3] ACI Committee 318, "Building Code Requirements for Structural Concrete (ACI 318-11) and Commentary”, American Concrete Institute, Farmington Hills, MI, 2011.

[4] CEN, Eurocode 8: "Design of Structures for Earthquake Resistance, Part 1: General Rules, Seismic Actions and Rules for Buildings, ENV 1998-1:2003", Comité Européen de Normalisation, Brussels, Belgium, 2004.

[5] CSA Committee, "Design of Concrete Structures, CSA A23.3-04", Canadian Standards Association, Mississauga, Canada, 2004.

[6] Federal Emergency Management Agency (FEMA), NEHRP Guidelines for the seismic rehabilitation of buildings, FEMA 356, Washington, U.S., 2000.

[7] P. Adebar, A.M.M. Ibrahim, and M. Bryson, "Test of high-rise core wall: Effective stiffness for seismic analysis", ACI Structural Journal, vol. 104, pp. 549-559, 2007.

[8] R. Ahmad, "Lateral stiffness of concrete shear walls for tall buildings", ACI Structural Journal, vol. 108, pp. 755-765, 2011.

[9] ATC, Modeling and Acceptance Criteria for Seismic Design and Analysis of Tall Buildings, ATC-72, Applied Technology Council, Berkeley, California, 2010.

[10] M. Gérin, and P. Adebar, "Accounting for shear in seismic analysis of concrete structures", 13th World Conference on Earthquake Engineering, Vancouver, Paper No. 1747, pp. 13, 2004.

[11] K. N. Rahal, "Post-cracking shear modulus of reinforced concrete membrane elements", Engineering Structures, vol. 32, pp. 218-225, 2010. 
[12] R. Park, and T. Paulay, "Reinforced Concrete Structures", John Wiley and Sons, Inc., New York, 1975.

[13] M. J. N. Priestley, F. Seible, and G. M. Calvi, "Seismic Design and Retrofit of Bridges", John Wiley \& Sons, Inc., New York, 1996.

[14] M. J. N. Priestley, and R. Park, "Strength and ductility of concrete bridge columns under seismic loading", ACI Structural Journal, vol. 84, pp. 61-76, 1987.

[15] M. Priestley, G. Calvi, and M. Kowalsky, "Displacement-based seismic design of structures", IUSS Press, Pavia, Italy, 2007.

[16] J. Krolicki, J. Maffei, and G. M. Calvi, "Shear strength of reinforced concrete walls subjected to cyclic loading", Journal of Earthquake Engineering, vol. 15, pp. 30-71, 2011.

[17] ACI Committee 318, "Building Code Requirements for Reinforced Concrete (ACI 318-71)", American Concrete Institute, Farmington Hills, MI, 1971, pp. 78.

[18] International Federation for Structural Concrete (Fib), "Seismic Assessment and Retrofit of Reinforced Concrete Buildings, fib Bulletin No. 24", State-of-art report by Task Group 7.1., 2003.

[19] M. J. N. Priestley, G. Ranzo, M. J. Kowalsky, and G. Benzoni, "Yield Displacement of Circular Bridge Columns", Proceeding of the Fourth Caltrans Seismic Workshop, Sacramento, July 1996.

[20] P. H. Miranda, G. M. Calvi, R. Pinho, and M. J. N. Priestley, "Displacement-based assessment of RC columns with limited shear resistance", ROSE Research Report No. 2005/04, IUSS Press, Pavia, Italy, 2005.

[21] T. N. Salonikios, A. J. Kappos, I. A. Tegos, and G. G. Penelis, "Cyclic load behaviour of low-slenderness reinforced concrete walls: Design basis and test results", ACI Structural Journal, vol. 96, pp. 649-660, 1999.

[22] T. N. Salonikios, "Analytical prediction of the inelastic response of RC walls with low aspect ratio", Journal of Earthquake Engineering, vol. 133, pp. 844-854, 2007.

[23] D. E. Branson, and T. Heinhrich, "Unified procedure for predicting the deflection and centroidal axis location of partially cracked nonprestressed and prestressed concrete members", ACI Structural Journal, vol. 79, pp.119-130, 1982.

[24] M. Khuntia, and S. K. Ghosh, "Flexural stiffness of reinforced concrete columns and beams: Experimental Verification", $A C I$ Structural Journal, vol. 101, pp. 364-374, 2004.

[25] H. Bachmann, "Neue Tendenzen im Erdbebeningenieurwesen", Beton- und Stahlbetonbau, vol. 99, pp. 356-371, 2004.

[26] C. Greifenhagen, "Seismic Behavior of Lightly Reinforced Concrete Squat Shear Walls", PhD thesis, Structural Engineering Institute (IS-IMAC), Ecole polytechnique fédérale de Lausanne, Switzerland, 2006.

[27] M. J. N. Priestley, and M. J. Kowalsky, "Aspects of drift and ductility capacity of rectangular cantilever structural walls", Bulletin of the New Zealand National Society for Earthquake Engineering, 1998.

[28] Y. B. Ho, "Enhancing the ductility of non-seismically designed reinforced concrete shear walls", Master Thesis, The Hong Kong University of Science and Technology, 2006.

[29] S. Shaingchin, P. Lukkunaprasit, and S. L. Wood, "Influence of diagonal web reinforcement on cyclic behavior of structural walls", Engineering Structures, vol. 29, pp. 498-510, 2007.

[30] R. K. L. Su, and S. M. Wong, "Seismic behaviour of slender reinforced concrete shear walls under high axial load ratio", Engineering Structures, vol. 29, pp. 1957-1965, 2007.

[31] Y. Zhang, and Z. Wang, "Seismic behavior of reinforced concrete shear walls subjected to high axial loading", ACI Structural Journal, vol. 97, pp.739-750, 2000.

[32] R. G. Oesterle, A. E. Fiorato, L. S. Johal, J. E. Carpenter, H. G. Russell, and W. G. Corley, "Earthquake Resistant Structural Walls - Tests of Isolated Walls", Report to National Science Foundation, Portland Cement Association, Skokie, IL, 1976.

[33] X. Liu, "Research on shear performance of CFST high-strength concrete shear wall", Master Thesis, Yangzhou University, 2013.

[34] T. N. Salonikios, "Shear strength and deformation patterns of R/C Walls With Aspect Ratio 1.0 and 1.5 Designed to Eurocode 8 (EC8)", Engineering Structures, vol. 24, pp. 39-49, 2002.

[35] A. Dazio, K. Beyer, and H. Bachmann, "Quasi-static cyclic tests and plastic hinge analysis of RC structural walls", Engineering Structures, vol. 31, pp.1556-1571, 2009.

[36] J. I. Daniel, K. N. Shiu, and W. G. Corley, "Openings in earthquake-resistant structural walls", Journal of Structural Engineering, ASCE, vol. 112, pp. 1660-1676, 1986.

[37] M. J. Kowalsky, and M. J. N. Priestley, "Improved analytical model for shear strength of circular reinforced concrete columns in seismic regions", ACI Structural Journal, vol. 97, pp. 388-396, 2000 .

[38] M. P. Collins, D. Mitchell, P. Adebar, and F. J. Vecchio, "A general shear design method", ACI Structural Journal, vol. 93, 1996.

[39] W. J. Carrillo, and S. M. Alcocer, "Shaking table tests of low-rise concrete walls for housing", Proceedings of 14th World Conference on Earthquake Engineering, Beijing, 2008.

[40] D. J. Kakaletsis, "Rotations of RC members of infilled frames at yielding and ultimate", The Open Construction and Building Technology Journal, vol. 6, (Suppl 1-M3), pp. 50-62, 2012.

[41] J. Landingin, H. Rodrigues, H. Varum, A. Arêde, and A. Costa, "Comparative analysis of RC irregular buildings designed according to different seismic design codes", The Open Construction and Building Technology Journal, vol.7, pp. 221-229, 2013

[42] SNZ, Structural Design Actions Part 5: "Earthquake Actions New Zealand, NZS 1170.5:2004", Standards New Zealand, Wellington, New Zealand, 2004.

(C) Tang and Su; Licensee Bentham Open.

This is an open access article licensed under the terms of the Creative Commons Attribution Non-Commercial License (http://creativecommons.org/licenses/by-nc/3.0/) which permits unrestricted, non-commercial use, distribution and reproduction in any medium, provided the work is properly cited. 